\title{
Recombinant Fsh and Lh therapy for spawning induction of 2 previtellogenic and early spermatogenic arrested teleost, the flathead grey mullet (Mugil cephalus)
}

4 Sandra Ramos-Júdez ${ }^{1}$, Ignacio Giménez ${ }^{2 *}$, Josep Gumbau-Pous ${ }^{1}$, Lucas Stephen ArnoldCruañes ${ }^{1}$, Alicia Estévez ${ }^{1}$ and Neil Duncan ${ }^{1 *}$

${ }^{1}$ IRTA, Sant Carles de la Ràpita Ctra. de Poble Nou km. 5.5, 43540 Sant Carles de la Ràpita, Tarragona, Spain.

${ }^{2}$ Rara Avis Biotec, S. L., Valencia, Spain.

\section{Abstract}

With the expansion and diversification of global aquaculture, efforts continue to develop new bio-technologies for assisted reproduction in species that present reproductive dysfunctions. Flathead grey mullet (Mugil cephalus) held in intensive conditions in the Mediterranean region, display a severe reproductive dysfunction, where males do not produce fluent milt and females are arrested at previtellogenesis or early stages of vitellogenesis. In the present study, weekly injections of species-specific single-chain recombinant gonadotropins (rGths); follicle stimulating hormone (rFsh) (6 to $12 \mu \mathrm{g} \mathrm{kg}^{-1}$ doses) and luteinizing hormone (rLh) (2.5 to $24 \mu \mathrm{g} \mathrm{kg}^{-1}$ doses) were administered to induce vitellogenesis, from previtellogenesis / early vitellogenesis to the completion of vitellogenic growth in females and enhance spermatogenesis to produce adequate volumes of sperm from non-fluent males. During the experiment, all treated females $(\mathrm{n}=$ 21) developed oocytes in late vitellogenesis with $603 \pm 8 \mu \mathrm{m}$ diameter and all treated males produced fluent sperm. To induce oocyte maturation, ovulation and spawning, females were treated with either (i) a priming dose of $30 \mu \mathrm{g} \mathrm{kg}^{-1}$ of $\mathrm{rLh}$ and a resolving dose of $40 \mathrm{mg} \mathrm{kg}^{-1}$ of progesterone ( $\mathrm{P}_{4}$ ), (ii) priming and resolving doses of $30 \mu \mathrm{g} \mathrm{kg}^{-1}$ of $\mathrm{rLh}$, or (iii) priming and resolving doses of $40 \mathrm{mg} \mathrm{kg}^{-1}$ of $\mathrm{P}_{4}$ given 24:05 \pm 0:40 h apart. Females were placed in spawning tanks with rGth treated males that had fluent sperm. Spontaneous spawns of fertilised eggs were obtained after inducing with $\mathrm{rLh}+\mathrm{P}_{4}$ or $\mathrm{rLh}$ $+\mathrm{rLh}$ (priming and resolving injections) with a spawning success of the $85 \%$ (8 of 9 females) and $100 \%(\mathrm{n}=6)$, respectively. The eggs collected from the tanks presented 64 $\pm 22 \%$ fertilization with embryo development and $57 \pm 24 \%$ hatching. The treatment $\mathrm{P}_{4}$ $+\mathrm{P}_{4}$ had a lower ovulation success (50\%-3 of 6 females) and spawning success $(17 \%)$ with no fertilised eggs. Success was independent of the initial gonadal stage of females. In comparison, control females did not show any advance in gonadal development from initial stages and control males did not produce fluent sperm. The present results confirm the possibility of controlling oogenesis from previtellogenesis to the completion of maturation and fertilised tank spawning using exclusively rFsh and $\mathrm{rLh}$ in a teleost species.

Keywords: Mugil cephalus, rFsh, rLh, spawns, eggs, larvae

* Corresponding authors: Neil Duncan ${ }^{1}$, Email: neil.duncan@irta.cat, Tel.: +34 977745427 extension: 1815 Ignacio Giménez ${ }^{2}$,Email: igimenez@ raraavis-bio.com 


\section{Introduction}

44 Intensive aquaculture is looking for ways to improve reproductive control, especially in reproductively dysfunctional species to ensure the supply of fry for large-scale commercial production. The development of culture protocols will not only ensure a consistent and sustainable supply for grow-out operations, but will also allow for genetic improvements through selective breeding. The success of culture protocols, will in turn alleviate the fishery pressure on stocks of natural populations that in many cases are

50 compromised. An essential part to provide a reliable supply of juveniles is to control the reproduction of adult fish held in captivity. However, some species do not complete reproduction in captivity and exogenous hormonal therapies have been employed to develop aquaculture production.

The two reproductive stages, gametogenesis (oogenesis and spermatogenesis) and maturation (oocyte maturation and spermiation) are controlled by different reproductive hormones produced in the pituitary and gonad, i.e., gonadotropin hormones (Gths) and steroids (Mañanós et al., 2009). Hormone therapies based on gonadotropin releasing hormones and luteinizing hormone receptor agonists (human chorionic gonadotropins or pituitary extracts) are commonly used to control the maturation phase, while hormonal control of gametogenesis is rarely used in the aquaculture industry (Mylonas and Zohar, 2007). The use of relatively new recombinant gonadotropin hormones (rGths), the recombinant follicle-stimulating $(\mathrm{rFsh})$ and luteinizing hormones $(\mathrm{rLh})$, can open new strategies in aquaculture to treat reproductive disorders and develop out-of-season breeding programs (Molés et al., 2020). To this end, different in vivo treatments have been developed, mainly focused on final maturation and spermiation/ovulation stages by single or double rGths injections (Aizen et al., 2017; Kobayashi et al., 2006). However, fish species arrested at the early stages of the reproductive cycle require control of gametogenesis, with long-term treatments of repeated injections that maintain elevated plasma levels of specific Gths (Molés et al., 2020). In the case of males, different successful long-term approaches have been described for immature European eel (Anguilla anguilla) (Peñaranda et al., 2018) and mature Senegalese sole (Solea senegalensis) (Chauvigné et al., 2018, 2017). In the case of females, it has been difficult to define similar long-term treatments to produce viable gametes from females arrested prior to vitellogenesis. A significant advance was achieved with the long-term treatment of previtellogenic flathead grey mullet (Mugil cephalus) females with rFsh and rLh to successfully complete vitellogenesis (Ramos-Júdez et al., 2021). However, after maturation induction with $\mathrm{rLh}$ and Progesterone $\left(\mathrm{P}_{4}\right)$, females held with spermiating males failed to spawn spontaneously. Therefore, gametes were stripped and artificially fertilised and a low percentage of fertilisation $(<1 \%)$ was obtained, which questioned the viability of the process for aquaculture purposes. However, despite of the low fertilisation, the study demonstrated the possibility of using rFsh and rLh to induce oogenesis from previtellogenesis to obtain eggs and larvae in intensive conditions and encouraged further research to improve the results obtained.

The flathead grey mullet, has a worldwide distribution in tropical, subtropical and temperate waters (McDonough et al., 2005), tolerance to wide ranges of salinities, excellent flesh quality and high growth rates. It represents an important species and a potential candidate in the diversification of aquaculture products mainly in the Mediterranean area, the Southeast of Asia, Taiwan, Japan and Hawaii (González-Castro and Minos, 2016). In the Mediterranean, flathead grey mullet spawn from July to October (Whitfield et al., 2012), however, breeders held in intensive conditions show reproductive 
dysfunctions; males rarely produce fluent milt (Aizen et al., 2005; De Monbrison et al., 1997; Yashouv, 1969) and females are found to be arrested at previtellogenesis (RamosJúdez et al., 2021) or early stages of vitellogenesis (Aizen et al., 2005).

94 The objective of the present study was to demonstrate that long-term treatment with rGths, rFsh and $\mathrm{rLh}$, can induce gametogenesis in flathead grey mullet males arrested with no fluent spermiation and females arrested at early stages of gametogenesis to obtain spawning of eggs with good fertilisation rates that provide viable larvae. Different treatments based on $\mathrm{rLh}$ and $\mathrm{P}_{4}$ were tested to induce oocyte maturation and spawning in females. As a final step, to check larval development and growth, the eggs obtained were used to carry out a preliminary larval rearing trial using a mesocosm technique.

\section{Material and methods}

\subsection{Broodstock maintenance}

104 A flathead grey mullet broodstock was formed with individuals, originally obtained from the Ebro River (Spain) or from a semi-extensive pond fish farm (Finca Veta La Palma,

106 Isla Mayor, Spain) and which had been held for 1.5 to 3.5 years in IRTA facilities (Sant Carles de la Ràpita, Spain). Thirty females with weights ranging from 0.9 to $2.4 \mathrm{~kg}$ and 108 standard length (SL) from 37 to $53 \mathrm{~cm}$, and fifteen males ranging from 0.7 to $1.3 \mathrm{~kg}$ and 34 to $43.5 \mathrm{~cm}$ were used. All fish were larger than the reported SL for first maturation in 110 this species (27 - $35 \mathrm{~cm}$ for females, $25-30 \mathrm{~cm}$ for males) (Whitfield et al., 2012). To identify individuals each fish was tagged intramuscularly with a Passive Integrated

112 Transponder (PIT) tag (Trovan®, ZEUS Euroinversiones S.L. Madrid, Spain). The sex of the individuals was determined by the presence or absence of oocytes obtained through

114 slight suction with a 1.67-mm plastic catheter inserted through the genital opening. Fish were maintained in $10 \mathrm{~m}^{3}$ covered tanks in a recirculating system (IRTAmar®) supplied

116 with $36 \%$ salinity water under natural conditions of light and controlled winter temperatures $\left(\geq 14^{\circ} \mathrm{C}\right)$ during the last year. Before the study, conducted from early August 118 to early November, the selected broodstock was transferred to another $10 \mathrm{~m}^{3}$ tank, water temperature was controlled at $23.1 \pm 0.2{ }^{\circ} \mathrm{C}$ and photoperiod was ambient (14L:10D -

120 11L:13D). Fish were fed 5 days a week at the rate of $1.5 \%$ of their body weight with a mix of two commercial marine fish diets; $90 \%$ mix of Le-2 and Le-5 Europa RG

122 (Skretting, Spain) and 10\% Brood Feed Lean (Sparos, Portugal). During all experimental procedures, for hormone administration and sampling, fish were anaesthetised with 73

$124 \mathrm{mg} \mathrm{L}^{-1}$ of MS-222. When required for the study, males were euthanised with an overdose of MS-222 (250 $\left.\mathrm{mg} \mathrm{L}^{-1}\right)$ and death was confirmed by a cut in the gills to exsanguinate the 126 fish.

\subsection{Hormonal induction}

\section{$128 \quad 2.2 .1$. Induction of vitellogenesis}

Females were assigned randomly to rGth and control groups taking care to have similar 130 distribution of females in different initial maturation stages in both groups. The control group (total $\mathrm{n}=9$ ) was formed with 6 females in previtellogenesis ( 5 in primary growth 132 and 1 in cortical alveoli step) and 3 in early vitellogenesis. A total of 21 females were assigned to receive the hormonal treatment; 12 females initially were in previtellogenesis

134 (8 in primary growth and 4 in cortical alveoli stage) and 9 in early vitellogenesis. Those females in early vitellogenesis had longer time in intensive captive conditions $(>2.25$ years) although not all females that were held for this time had started vitellogenesis. 
Single chain recombinant Mugil cephalus rFsh and $\mathrm{rLh}$ produced in Chinese hamster ovary (CHO) cells were purchased from Rara Avis Biotec S.L. (Valencia, Spain). Mugil cephalus rFsh was supplied with a concentration of $12 \mu \mathrm{g} \mathrm{mL} \mathrm{m}^{-1}$ and $\mathrm{rLh}$ with concentration of $8 \mu \mathrm{g} \mathrm{mL}^{-1}$. A methodology based on the protocol described by RamosJúdez et al. (2021) was followed. The pattern of application of rFsh and $\mathrm{rLh}$ aimed to

142 mimic the physiological variations of Fsh and Lh associated with natural reproductive development; initially only $\mathrm{rFsh}$ was administered during the early stages of 144 gametogenesis and, subsequently, a decrease in $\mathrm{rFsh}$ with an increase of rLh to regulate late gametogenesis (Lubzens et al., 2010). The protocol was applied according to ovarian

146 development (Fig 1). Increasing weekly doses of 6,9 and $12 \mu \mathrm{g} \mathrm{kg}^{-1} \mathrm{rFsh}$ were administered intramuscularly to induce previtellogenesis $(\sim 100 \mu \mathrm{m}$ oocyte diameter $)$ to 148 vitellogenesis (> $200 \mu \mathrm{m}$ ). Weekly doses were maintained at $12 \mu \mathrm{g} \mathrm{kg}^{-1}$ during vitellogenesis. As vitellogenesis progressed and when mean diameter of the most 150 developed oocytes was $\geq 300 \mu \mathrm{m}$, females received in addition a weekly administration of $\mathrm{rLh}$ at rising doses. A dose of $2.5 \mu \mathrm{g} \mathrm{kg}^{-1}$ was maintained until females entered into 152 late-vitellogenesis ( $\geq 400 \mu \mathrm{m}$ ) (Greeley et al., 1987) and was then increased to 4 and $6 \mu \mathrm{g}$ $\mathrm{kg}^{-1}$. At an oocyte diameter of $\sim 500 \mu \mathrm{m}$, weekly rFsh doses were reduced to $4 \mu \mathrm{g} \mathrm{kg}^{-1}$

154 while rLh was increased to $9 \mu \mathrm{g} \mathrm{kg}^{-1}$. A combination of $4 \mu \mathrm{g} \mathrm{kg}^{-1} \mathrm{rFsh}$ and $12 \mu \mathrm{g} \mathrm{kg}^{-1} \mathrm{rLh}$ per week was administered until vitellogenic growth was completed. The completion of oocyte growth was determined when oocytes were deemed approaching maturation; microscopic examination showed that the most developed oocytes were nearing $600 \mu \mathrm{m}$ in diameter. The nine females in the control group were also manipulated each week and were injected with saline solution $(1 \mathrm{~mL})$ a total of twelve times.

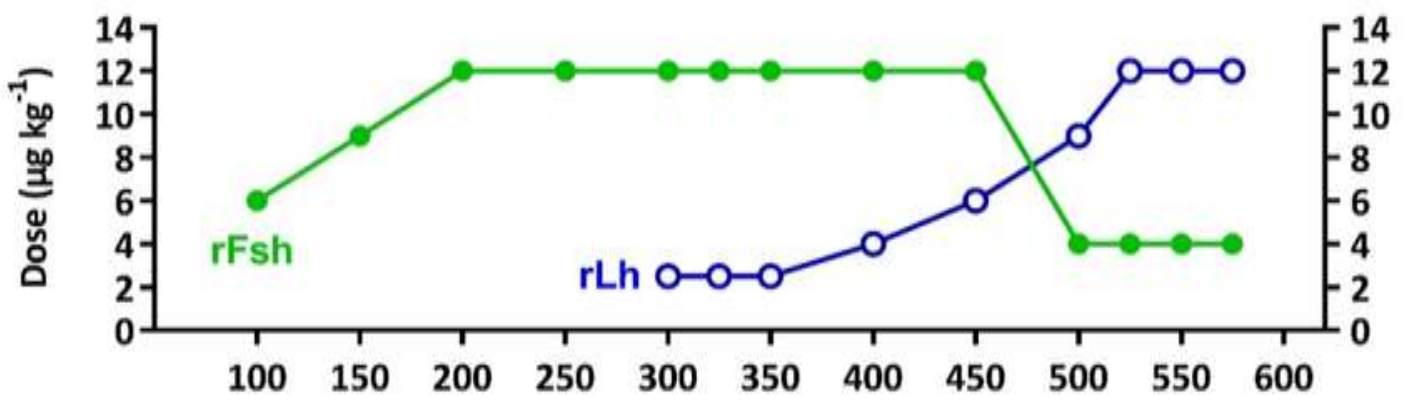

Reference oocyte diameter $(\mu \mathrm{m})$

162 Figure 1. Schematic representation of the rFsh and rLh treatment applied to flathead grey mullet females $(\mathbf{n}=\mathbf{2 1})$. The protocol was applied according to the development of female gonads determined by 164 ovarian biopsies. Weekly doses of 6, 9 and $12 \mu \mathrm{g} \mathrm{kg}-1 \mathrm{rFsh}$ were applied to induce previtellogenesis $(\sim 100$ $\mu \mathrm{m}$ oocyte diameter) to vitellogenesis (> $200 \mu \mathrm{m})$ and vitellogenic growth was maintained with a dose of

$16612 \mu \mathrm{g} \mathrm{kg}-1$ per week. When the mean diameter of the largest oocytes was $\geq 300 \mu \mathrm{m}$, in addition to rFsh, $\mathrm{rLh}$ was administered in increasing doses. A dose of $2.5 \mu \mathrm{g} \mathrm{kg}-1$ was maintained until females presented $\geq$ $400 \mu \mathrm{m}$ oocytes and was raised to 4 and $6 \mu \mathrm{g} \mathrm{kg-1} \mathrm{rLh}$. At $\sim 500 \mu \mathrm{m}$ diameter, weekly rFsh doses were reduced to $4 \mu \mathrm{g} \mathrm{kg}-1$ whereas $\mathrm{rLh}$ was increased to $9 \mu \mathrm{g} \mathrm{kg}-1$. A combination of $4 \mu \mathrm{g} \mathrm{kg}-1 \mathrm{rFsh}$ and $12 \mu \mathrm{g}$

$170 \mathrm{~kg}-1 \mathrm{rLh}$ per week were administered until vitellogenic growth was completed $(\sim 600 \mu \mathrm{m})$. Each point corresponds to a weekly administration. This scheme represents the longest pattern of administration of those females that required a total of thirteen weeks to complete vitellogenic growth. 
174 Assessment of gonadal development was undertaken on alternate weeks by ovarian biopsies obtained by slight suction through a plastic cannula. Fresh ovarian samples were 176 examined under a microscope $(\times 40$ magnification), to measure the mean diameter of the largest most advanced oocytes $(n=20$ per female) and a sample fixed for histology. Blood

178 samples were obtained before the initial treatment (week 0) and when vitellogenic growth was completed in the treated group and at the end of the experiment in the control group.

\subsubsection{Hormonal administration in males}

In parallel, males were assigned randomly to rGth and control groups taking care to have similar distribution of males in different initial maturation stages in both groups. The control group (total $n=6$ ) was formed with 5 males with no presence of sperm and 1 with

184 a presence of sperm (sperm index 1, presence of sperm, but not fluid, see below). A total of 9 males were assigned to receive the hormonal treatment; 7 males with no presence of 186 sperm and 2 with presence of sperm. Males treated with rGth were split into two groups that received the same treatment, but at different times in the experimental period. The reason was to assure the availability of spermiating males for spawning induction when the females completed vitellogenic growth. Group 1 of males $(n=4$ treated, $n=3$ control) 190 initiated the treatment on week 1 and the group $2(n=5$ treated, $n=3$ control) on week 3 (Fig 2). The aim of the treatment was to apply rGths according to their described role in spermatogenesis. Increasing doses of $\mathrm{rFsh}\left(6,9\right.$ and $\left.12 \mu \mathrm{g} \mathrm{kg}^{-1}\right)$ were administered at early spermatogenesis and high levels $\left(12 \mu \mathrm{g} \mathrm{kg}^{-1}\right)$ during testicular growth (Fig 3). No rLh was administered during early spermatogenesis, both $\mathrm{rFsh}$ and $\mathrm{rLh}\left(12 \mu \mathrm{g} \mathrm{kg} \mathrm{kg}^{-1}\right.$ of both $\mathrm{rFsh}$ and $\mathrm{rLh}$ ) during the middle stages of testicular growth and only rLh $\left(12 \mu \mathrm{g} \mathrm{kg}^{-1}\right)$ was administered at late stages to induce sperm maturation (Schulz et al., 2010). Group 1 received the treatment for a total of 12 weeks whereas group 2 for 10 weeks. At week 9 , group 1 received a dose of $12 \mu \mathrm{g} \mathrm{kg}^{-1} \mathrm{rFsh}$ instead of $\mathrm{rLh}$ as a reduction in the spermiation stage was observed (see 3.2 section). Doses were in the range of previous studies with males using rGths produced in CHO cells (Chauvigné et al., 2018, 2017; Peñaranda et al., 2018; Ramos-Júdez et al., 2021). Control males were injected with $1 \mathrm{~mL}$ of saline solution per week.

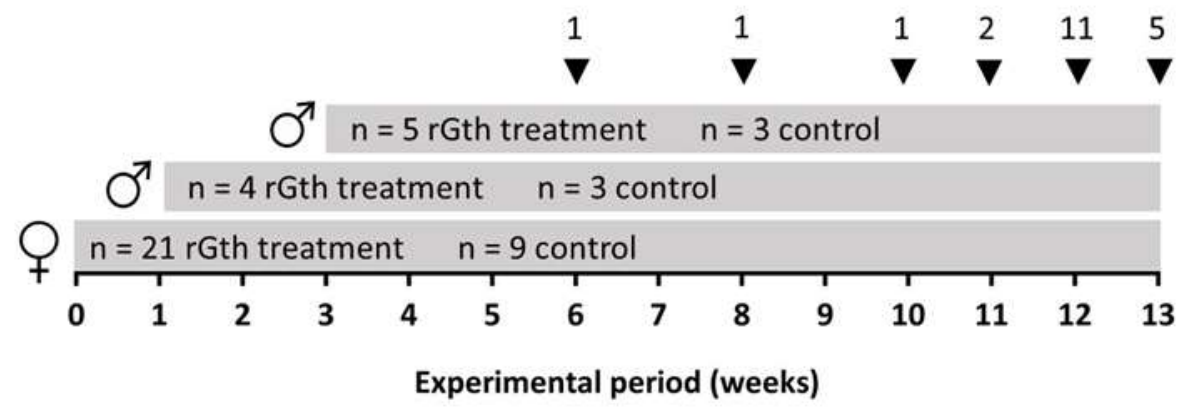

204 Figure 2. Overall scheme of the experiment. Females receiving the rGths treatment were injected weekly until completion of vitellogenic growth which took place in a maximum period of thirteen weeks, following thirteen administrations. Arrow heads indicate the moment in which individual females were induced to spawn (number of females indicated by the number on the top). Control females received a total of twelve saline injections. Group 1 of males started the treatments (rGth treatment and saline) on week 1, whereas the group 2 on week 3 . 


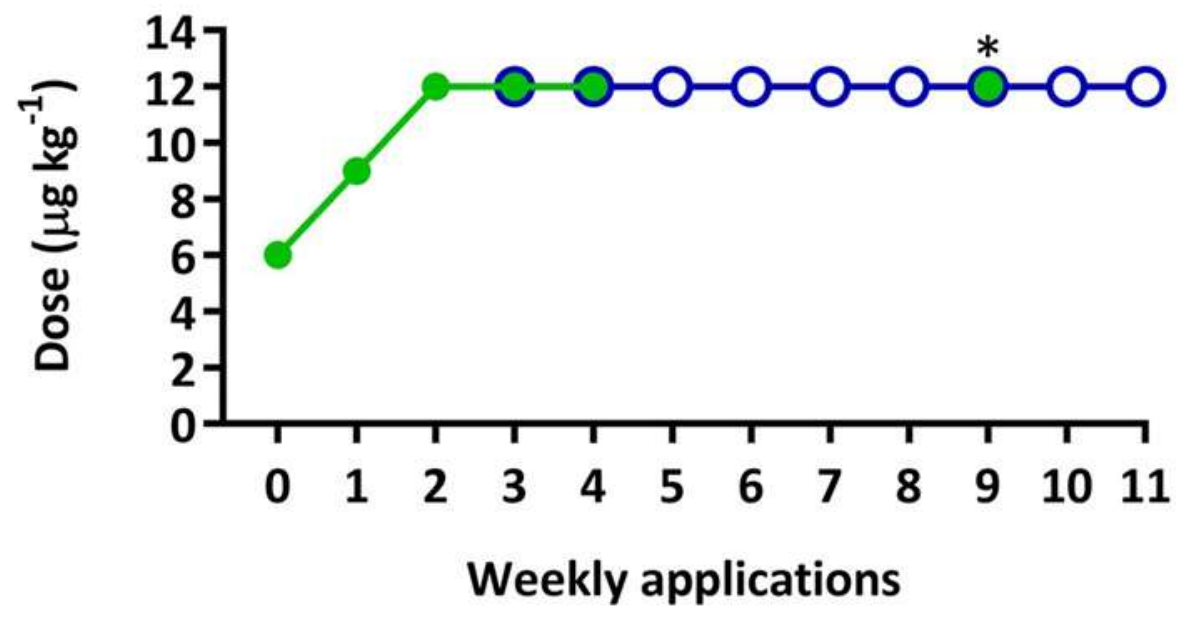

212 Figure 3. Diagram of the hormonal treatment of flathead grey mullet males. Asterisk indicates the moment that group 1 received $12 \mu \mathrm{g} \mathrm{kg-1}$ of $\mathrm{rFsh}$ instead of $\mathrm{rLh}$. Green indicates rFsh administration and blue indicates $\mathrm{rLh}$ administration.

216 In order to evaluate the progression of maturation, at the beginning of the treatment and on a weekly basis, a gentle squeeze on the ventral abdomen toward the urogenital opening 218 was applied to release the sperm. Spermiation stage was determined on a scale from 0 to 3 ( $0=$ not fluent, $1=$ fluent but no sample can be obtained, $2=$ fluent, 3 = very fluent $)$.

220 By this method, only mature cells are released together with the seminal plasma. Therefore, to determine the stage of development in males, some males were sacrificed 222 at the beginning $(n=2)$ and the end of the treatment $(n=2$ per group) and the testes removed for histological procedures and the measurement of gonadosomatic index (GSI: 224 testes weight/fish weight x 100). Towards the end of the experiment (weeks 10 and 13), sperm samples from running males were collected, total volume recorded and stored at

$2264^{\circ} \mathrm{C}$ for sperm quality analysis. Blood samples were also taken from treated and control males each two weeks of the treatment.

\subsubsection{Oocyte final maturation and spawning induction}

Three different treatments were followed for maturation and spawning induction.

230 Females that completed vitellogenic growth (as determined by gonadal biopsy) and males with running milt (spermiating stage 2 or 3 ) were selected for spawning induction. The individuals were separated from the main group and stocked in a separate $10-\mathrm{m}^{3}$ tank per treatment. The three separate tanks had the same conditions as the holding tank. One male

234 in each spawning tank received a dose of $24 \mu \mathrm{g} \mathrm{kg}^{-1}$ of rLh while the others followed the hormonal treatment previously described, receiving $12 \mu \mathrm{g} \mathrm{kg}^{-1}$ of $\mathrm{rLh}$. The selected females were injected intramuscularly with either (i) priming $\mathrm{rLh}$ and resolving Progesterone ( $\left.\mathrm{P}_{4}\right)$ (Prolutex, IBSA Group, Italy) as in Ramos-Júdez et al. (2021), (ii) rLh

238 for priming and resolving injections or (iii) $\mathrm{P}_{4}$ for priming and resolving injections (doses in Table 1). Priming and resolving injections were administered 24:05 \pm 0:40 h apart.

240 Ovarian samples were taken with a cannula and examined before each administration. Maturation and ovulation induction of females from each treatment group was staggered on different consecutive days in order to separate the different spawning events. 
bioRxiv preprint doi: https://doi.org/10.1101/2021.09.29.462352; this version posted October 1, 2021. The copyright holder for this preprint (which was not certified by peer review) is the author/funder, who has granted bioRxiv a license to display the preprint in perpetuity. It is made available under aCC-BY-NC-ND 4.0 International license.

244

252

Table 1. Treatments to induce maturation and spawning in flathead grey mullet (Mugil cephalus) females and the results obtained. Latency period indicates the time (h) between resolving injection and spawning; Ovulation success (\%) indicates the number of females that ovulated after the resolving injection divided by the total number of injected females; Spawning success $(\%)$ indicates the number of females that spawned naturally in the tank after the resolving injection, divided by the total number of injected females. Data are expressed as mean \pm standard deviation. Oocyte diameter, total eggs per female and fecundity between the three treatments were compared by one-way ANOVA while latency period, percentages of initial fertilization, embryo survival, hatching and hatching in 96-well plate between the successful treatments $\left(\mathrm{rLh}+\mathrm{rLh}\right.$ and $\left.\mathrm{rLh}+\mathrm{P}_{4}\right)$ were compared through a t-student test.

\begin{tabular}{|c|c|c|c|}
\hline Group & $\mathrm{rLh}+\mathrm{P}_{4}$ & $\mathrm{rLh}+\mathrm{rLh}$ & $\mathrm{P}_{4}+\mathrm{P}_{4}$ \\
\hline Treatment Priming injection & $30 \mu \mathrm{g} \mathrm{kg}^{-1} \mathrm{rLh}$ & $30 \mu \mathrm{g} \mathrm{kg}^{-1} \mathrm{rLh}$ & $40 \mathrm{mg} \mathrm{kg}^{-1} \mathrm{P}_{4}$ \\
\hline Treatment Resolving injection & $40 \mathrm{mg} \mathrm{kg}^{-1} \mathrm{P}_{4}$ & $30 \mu \mathrm{g} \mathrm{kg}^{-1} \mathrm{rLh}$ & $40 \mathrm{mg} \mathrm{kg}^{-1} \mathrm{P}_{4}$ \\
\hline Oocyte diameter $(\mu \mathrm{m})$ & $606 \pm 10^{\mathrm{a}}$ & $602 \pm 6^{\mathrm{a}}$ & $600 \pm 7^{a}$ \\
\hline No. of injected females & 9 & 6 & 6 \\
\hline No. of spawned females & 8 & 6 & 1 \\
\hline Latency period (h) & $16: 36 \pm 1: 56^{\mathrm{a}}$ & $16: 51 \pm 2: 22^{a}$ & $24: 30: 00$ \\
\hline Ovulation success $(\%)$ & 100 & 100 & 50 \\
\hline Spawning success $(\%)$ & 89 & 100 & 17 \\
\hline Total eggs per female & $\begin{array}{c}1,760,100 \pm \\
821,102^{\mathrm{a}}\end{array}$ & $\begin{array}{c}1,631,889 \pm \\
954,138^{\mathrm{a}}\end{array}$ & $\begin{array}{c}1,280,833 \pm \\
966,42^{\mathrm{a}}\end{array}$ \\
\hline Fecundity (egg kg $\left.{ }^{-1} \mathrm{bw}\right)$ & $\begin{array}{c}1,194,637 \pm \\
635,747^{\mathrm{a}}\end{array}$ & $\begin{array}{c}1,205,1387 \pm \\
487,002^{\mathrm{a}}\end{array}$ & $\begin{array}{c}694,529 \pm \\
526,457^{\mathrm{a}}\end{array}$ \\
\hline Initial fertilization $(\%)$ & $\begin{array}{c}49 \pm 23^{\mathrm{a}} \\
(8 \min -80 \max )\end{array}$ & $\begin{array}{c}60 \pm 16^{\mathrm{a}} \\
(39 \min -84 \max )\end{array}$ & 0 \\
\hline Embryo survival (\%) & $\begin{array}{c}56 \pm 22^{\mathrm{a}} \\
(15 \min -80 \max )\end{array}$ & $\begin{array}{c}73 \pm 21^{\mathrm{a}} \\
(42 \min -90 \max )\end{array}$ & 0 \\
\hline Hatching $(\%)$ & $\begin{array}{c}57 \pm 21^{\mathrm{a}} \\
(25 \min -88 \max )\end{array}$ & $\begin{array}{c}61 \pm 30^{\mathrm{a}} \\
(23 \min -90 \max )\end{array}$ & - \\
\hline Hatching 96-well plate (\%) & $95 \pm 4^{\mathrm{a}}$ & $97 \pm 1^{\mathrm{a}}$ & - \\
\hline
\end{tabular}

The sex ratio was $1: 2$ or 1:3 (female : male) per spawning event depending on availability of males. After all the spawning events, males were returned back with the main group to the initial tank. In the cases where females ovulated and showed a swollen belly, but did not release the eggs, manual stripping was applied.

Parallelly, oocytes obtained from cannulation from females $(n=6)$ that had received the priming injection of $\mathrm{rLh}\left(30 \mu \mathrm{g} \mathrm{kg}^{-1}\right)$ were incubated in vitro with different hormones. A total of $58.7 \pm 29.9$ oocytes were incubated in a well of a 96-well plate with $200 \mu \mathrm{L}$ of Leibovitz's L-15 medium, with either no hormone (control), rLh (concentrations of 400, 200, 100, 50 and $\left.10 \mathrm{ng} \mathrm{mL}^{-1}\right)$, rFsh $\left(400,200,100,50\right.$ and $\left.10 \mathrm{ng} \mathrm{mL}^{-1}\right)$ or $\mathrm{P}_{4}(4000,1000$, 500 and $50 \mathrm{ng} \mathrm{mL}^{-1}$ ). Each treatment was applied in triplicate to oocytes from each female. After 48 hours of incubation at $21^{\circ} \mathrm{C}$, the follicles were examined under a binocular microscope and oocytes without the follicular layer (ovulated) and intact follicles (un-ovulated) were counted for each well. 


\subsection{Egg collection and incubation}

Surface out-flow egg collectors (mesh size of $500 \mu \mathrm{m}$ ) were placed to receive eggs from

270 the tanks and were frequently inspected for eggs. When spawning was observed, eggs were transferred into a $10 \mathrm{~L}$ bucket. The number of eggs per spawn (fecundity) was

272 estimated by counting the eggs in triplicate subsamples. A sample of eggs $(n=50-100)$ was observed under a microscope and the percentage $(\%)$ fertilization for each batch of

274 spawned eggs was determined by calculating the \% of eggs that reached the 2- to 16-cell stage. Eggs for incubation were collected after careful agitation of the eggs in the $10 \mathrm{~L}$

276 bucket. The eggs were incubated at a density of 13,230 \pm 7,273 eggs L ${ }^{-1}$ in $30 \mathrm{~L}_{\text {incubators }}$ with the same conditions as the broodstock holding tanks. Each incubator was supplied

278 with an air stone placed down in the centre to maintain the eggs in suspension and prevent accumulation of the eggs at the surface or bottom of the incubator. The number of eggs

280 in each incubator was estimated by mixing the incubator homogenously and taking three $100 \mathrm{~mL}$ samples and counting the eggs in each sample. The eggs were left one day to

282 develop and survival rate (percentage of eggs with embryos) was estimated as for percentage fertilization with a sample of eggs $(n=50-100)$ taken from the incubator.

284 The following day, the number of hatched larvae in each incubator was estimated volumetrically as for the eggs. In parallel to the 30L incubators, fertilised eggs were

286 transferred into individual wells filled with sterile seawater in a 96-well cell culture plate (EIA plate) and placed in a refrigerated incubator at $21^{\circ} \mathrm{C}$ in duplicate for each spawn and

288 revised daily until the last larva died, to estimate hatching rate and larval survival under starvation as in Giménez et al. (2006). Percentage of survival was calculated as the

290 number of larvae alive / total hatched larvae.

A preliminary trial was made to examine the larval growth and development. The trial

292 did not focus on survival as the facilities and staff were not available to provide optimal conditions for the larvae. Larval rearing was carried out using mesocosm conditions

294 (Divanach and Kentouri, 2000), with low larval density in a large tank (6 larvae $\mathrm{L}^{-1}, 1500$ L tank) under more natural or, at least, less strict conditions than those used in intensive 296 rearing, and using an endogenous bloom of wild marine zooplankton, mostly harpacticoid copepods, together with periodic addition of rotifers and Artemia spp nauplii. The trial 298 was carried out from November $11^{\text {th }}$ to December $18^{\text {th }} 2020$ using larvae 4 days post hatch (dph) that hatched on November $7^{\text {th }}$, from a spawn obtained with the $\mathrm{rLh}+\mathrm{rLh}$ spawning

300 treatment. The larvae were stocked in a $1500 \mathrm{~L}$ tank at $20^{\circ} \mathrm{C}, 12 \mathrm{hL}: 12 \mathrm{hD}$ photoperiod and fed on rotifers for 26 days ( 4 to $30 \mathrm{dph}$ ) followed by newly hatched Artemia nauplii (24

302 - 39 dph). Phytoplankton (a mixture of Tetraselmis suecica and Isochrysis galbana) was added every day in order to maintain a green medium, and every two days the rotifer

304 concentration was assessed to maintain a density of $5 \mathrm{rot} \mathrm{mL}^{-1}$. Artemia nauplii were added when the larvae reached $4.3 \mathrm{~mm}$ TL (20 dph) being the main food for larvae after

$3065 \mathrm{~mm}$ TL as suggested by Hagiwara et al. (1992). Ten larvae arbitrarily chosen were sampled at 4, 6, 9, 11, 17, 23, 27, 32, 37 and $39 \mathrm{dph}$ and anaesthetised with MS-222.

308 Standard length was measured using a digital camera connected to an image analyser (AnalySIS, SIS Gmbh, Germany). Photographs were also used to estimate the presence

310 or absence of food in the gut and to examine swim bladder inflation as well as other indicators of larval development.

\section{2.4. Histological analysis}

Ovarian samples obtained by cannulation and testis portions were preserved in Bouin's 314 fluid for $24 \mathrm{~h}$ and stored in $70 \%$ ethanol until processed. The dehydrated tissues were embedded in paraffin and $3 \mu \mathrm{m}$ sections cut. The testes portions (from the anterior, middle 
316 and posterior part) were oriented to obtain horizontal sections. Cut sections were stained with hematoxylin and eosin (Casa Álvarez, Spain) for morphological evaluation. The slides were examined under a light microscope (Leica DMLB, Houston, USA).

Oocytes were classified as previously described by Ramos-Júdez et al., (2021). Oocytes were classified as previtellogenic: with primary growth (PG) oocytes, which presented multiple nucleoli situated in the germinal vesicle, or with cortical alveoli (SGca) oocytes that had small oil droplets and granular vesicles in the peripheral ooplasm. The incorporation of yolk globules indicated vitellogenic stages: early secondary growth

324 (SGe), late-secondary growth (SGl) when oocytes reached $\geq 400 \mu \mathrm{m}$ (Greeley et al., 1987) and full-grown secondary growth oocytes (SGfg) when the vitellogenic growth was 326 completed with the fusion of yolk granules and thickening of vitelline membrane. Oocytes were classified as oocyte maturation stage $(\mathrm{OM})$ when oil droplets were coalescing and

328 the nucleus was positioned to one side of the oocyte, indicating the initiation of the germinal vesicle migration (GVM). Oocytes with disintegrating structure and 330 hypertrophy were in atresia (Valdebenito et al., 2011). Maturation stage of females was determined according to the most developed stage of oocytes present. Additionally, the

332 percentage of oocytes in different stages in the ovaries among weeks was calculated through the identification of $\geq 50$ random oocytes per female each week.

334 To evaluate testes samples, the number of spermatogonia (SPG) type A and B, spermatocytes (SPC), spermatids (SPD) and spermatozoa (SPZ) were scored in 12 336 seminiferous tubules randomly selected from different areas (anterior, middle and posterior) per sample and the percentage abundance of each germ cell type was 338 determined.

\subsection{Sperm quality evaluation}

340 Sperm samples from running males were collected, for quality evaluation, on week 10 and week 13 at the end of the experimental period. Samples were collected in a $1 \mathrm{~mL}$

342 syringe avoiding the contamination by urine, faeces and water. Sperm was divided into two aliquots, one was maintained as undiluted sperm and one was diluted 1:10 (1 part

344 sperm + 9 parts diluent) in Marine Freeze ${ }^{\circledR}$ (IMV Technologies, L'Aigle, France) extender (González-López et al., 2020) and both samples were maintained in Eppendorf 346 tubes at $4^{\circ} \mathrm{C}$ until evaluation. Sperm was activated by pipetting $5 \mu \mathrm{L}$ of the sperm sample (undiluted or diluted) into an Eppendorf with, depending on the concentration of the 348 sperm, 195, 295, 495 or $995 \mu \mathrm{L}$ of sea water. Immediately, the Eppendorf was agitated to thoroughly mix, then $2 \mu \mathrm{L}$ containing activated sperm was pipetted into an ISAS counting 350 chamber (Integrated Sperm Analysis System, Spain), and videos of tracks of the activated spermatozoa were recorded $15 \mathrm{~s}$ after activation with the CASA system SCA-VET-01

352 (Microptic, Barcelona, Spain). Videos were recorded using a digital camera (Basler Ace ACA1300-200UC, Basler AG, Ahrensburg, Germany) connected to an optical phase-

354 contrast microscope (Nikon Eclipse Ci, Tokyo, Japan) with $\times 10$ negative phase contrast objective. The following sperm parameters were determined: (1) sperm concentration

356 (spz mL $\left.\mathrm{m}^{-1}\right),(2)$ sperm motility (\%), (3) rapid progressive sperm (\%), and (4) sperm velocity $\left(\mu \mathrm{m} \mathrm{s}^{-1}\right)$ : the curvilinear velocity (VCL), straight-line velocity (VSL) and average

358 path velocity (VAP). The CASA program was set to classify motile sperm to have a VCL of $>25 \mu \mathrm{m} \mathrm{s}^{-1}$ and fast progressive sperm to have a straightness (SRT = VSL/VAP x 100) 360 of $>80 \%$ and a VCL of $>80 \mu \mathrm{m} \mathrm{s}^{-1}$. All samples were analysed on the day of the collection and $48 \mathrm{~h}$ after collection. Samples collected at the end of the experiment (week 13) were also analysed on days 1, 4, 6, 8, 11, 13 and 15 after collection. 


\subsection{Steroid hormone determination}

364 Blood samples were collected and centrifuged at 3,000 rpm at $4{ }^{\circ} \mathrm{C}$ for $15 \mathrm{~min}$ and the plasma stored at $-80{ }^{\circ} \mathrm{C}$ until analysis. Plasma levels of $17 \beta$-estradiol $\left(\mathrm{E}_{2}\right)$ and 11 -

366 ketotestosterone (11-KT) were analysed using commercially available enzyme immunoassays (EIA) (Cayman Chemical Company, USA). Steroids were extracted with 368 methanol that was evaporated and extracts were re-suspended 1:10 $\left(\mathrm{E}_{2}\right)$ or 1:100 (11-KT) in the EIA buffer.

\section{$370 \quad$ 2.7. Statistical analysis}

Data is expressed as the mean \pm standard deviation (SD). A Chi-square test was used to 372 examine the distribution between groups, of fish that had different maturational stages at the start of the experiment and whether fish that ovulated or spawned had a determinate 374 maturity status at the beginning of the experiment. Shapiro-Wilk and Levene tests were used to check the normality of data distribution and homogeneity of variance,

376 respectively. Mann-Whitney U test or Kruskal-Wallis test, followed by Dunn's pairwise comparison, were used in non-normally distributed data to compare oocyte diameter

378 between treated and control group within a week and between weeks during the experiment, respectively. One-way ANOVA followed by Holm-Sidak post hoc test was 380 used to separately examine differences in the independent variables of diameter of fullgrown oocytes, percentage of OM, total eggs per females, and fecundity between the three 382 spawning treatments. Variances across the groups were not equal for the GSI data, which was log-transformed and groups compared using the Brown-Forsythe test and Games-

384 Howell post-hoc multiple comparisons test. Spawning data from $\mathrm{rLh}+\mathrm{rLh}$ and $\mathrm{rLh}+\mathrm{P}_{4}$ spawning treatments (i.e., latency period, fertilization and hatching percentages) was

386 compared using a t-student test. Differences in percentage of OM and oocyte diameter before and after the priming or resolving injections, and percentage ovulation of oocytes

388 incubated in vitro were examined by one-way repeated measures (RM) ANOVA with individual females as the subject. Two-way RM ANOVA with pairwise comparison by 390 the Holm-Sidak test was used for comparing $\mathrm{E}_{2}$ and 11-KT between weeks and treatment groups. Sperm quality parameters were compared with a one-way and two-way RM

392 ANOVA. In the one-way RM ANOVA, the male was the subject, day of storage the independent variable and sperm quality parameters the dependent variables. In the two394 way RM ANOVA, the male was the subject, time of storage (0 or 48h) and sample dilution (undiluted or Marine Freeze $($ ) ) were the independent variables and sperm quality 396 parameters the dependent variables. Significant differences were detected at a significance level of $\mathrm{P}<0.05$. Statistical analyses were performed with SigmaPlot version

39812.0 (Systat Software Inc., Richmond, CA, USA), with the exception of the BrownForsythe test that was conducted with SPSS software version 20.0 (Armonk, NY: IBM 400 Corp).

\subsection{Ethics statement}

402 The study was conducted in accordance with the European Directive 2010/63/EU of 22nd September on the protection of animals used for scientific purposes; the Spanish Royal 404 Decree 53/2013 of February 1st on the protection of animals used for experimentation or other scientific purposes; the Catalan Law 5/1995 of June 21th, for protection of animals used for experimentation or other scientific purposes and the Catalan Decree 214/1997 of July 30th for the regulation of the use of animals for the experimentation or other scientific purposes. The procedures used were evaluated by IRTA's Committee of Ethics 
bioRxiv preprint doi: https://doi.org/10.1101/2021.09 29.462352; this version posted October 1, 2021. The copyright holder for this preprint (which was not certified by peer review) is the author/funder, who has granted bioRxiv a license to display the preprint in perpetuity. It is made available under aCC-BY-NC-ND 4.0 International license.

and Experimental Animal (CEEA) and the Catalan Government and procedures authorized with ID V7MH4802M.

\section{Results}

\subsection{Induction and completion of vitellogenesis}

414 Induction and completion of vitellogenesis $(603 \pm 8 \mu \mathrm{m})$ from previtellogenic and early vitellogenic females was achieved with $100 \%$ success in the rGth-treated group; as 416 observed for all 12 previtellogenic females and all 9 early vitellogenic females. No females from the control group completed oocyte growth (Fig 4A).

A
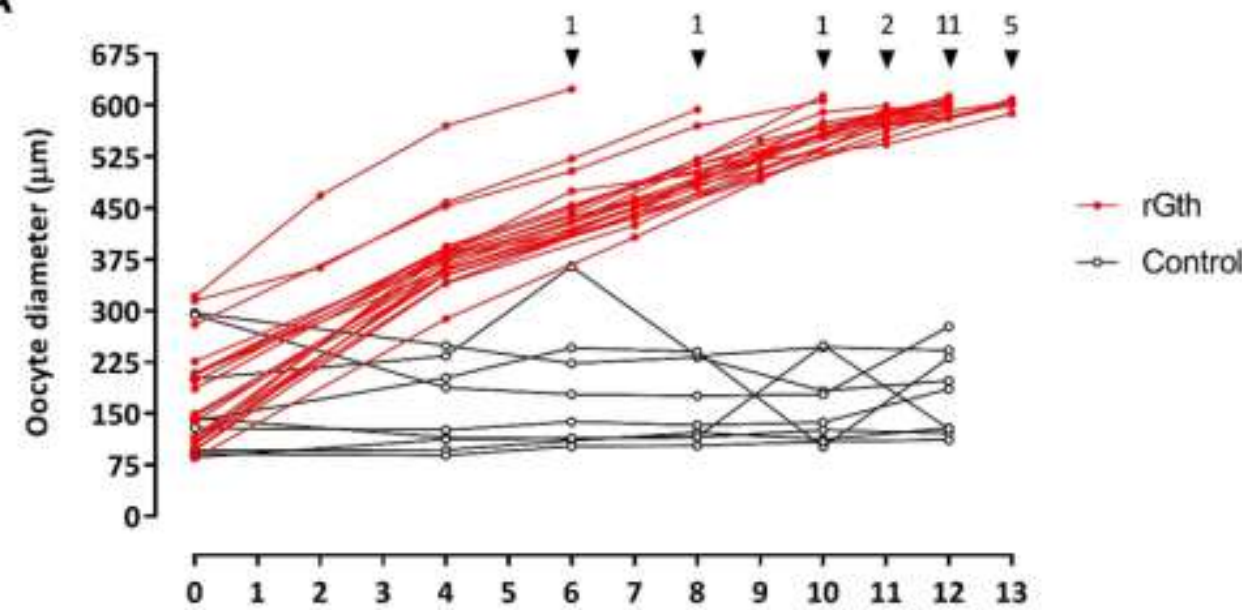

B

Experimental period (weeks)

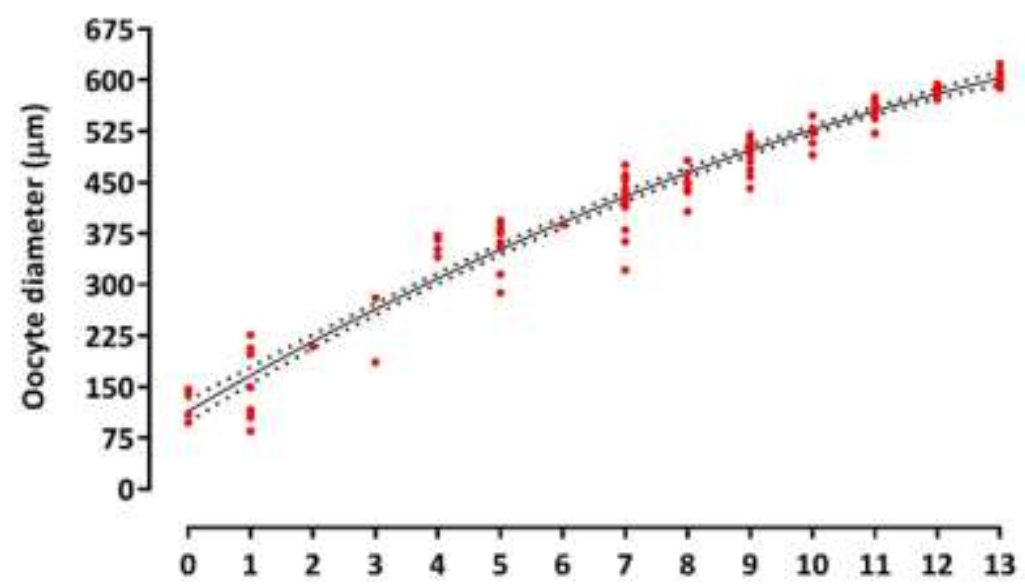

Number of weeks prior to completion of vitellogenic growth

Figure 4. Mean oocyte diameter of the largest most developed oocytes $(n=20$ per female) in wet mounts in each female (represented by a line). (A) Females that received the rFsh and $\mathrm{rLh}$ treatment (n $=21)$ and females that received saline injections (control) $(\mathrm{n}=9)$. Triangles show the moment and the number of females that completed vitellogenic growth and were selected for maturation and ovulation induction. (B) Mean diameter of the oocytes of rGth-treated females aligned from the completion of vitellogenic growth, the moment that were selected for maturation and spawning induction. The growth of oocytes in represented by a second order polynomial (quadratic) equation $\left(\mathrm{R}^{2}=0.9625\right)$. 
At the beginning of the experiment, females in different stages of ovarian development were evenly distributed between the control and treatment groups $\left(\chi^{2}=0.824 ; \mathrm{gl}=2 ; \mathrm{P}=\right.$ 0.662). Control and rGths groups had $62 \pm 7 \%$ of females in previtellogenesis (from 430 which the $61 \pm 7 \%$ and $23 \pm 16 \%$ were at primary growth and at cortical alveoli, respectively) and $38 \pm 7 \%$ in early vitellogenesis (Fig 5A, 5B) with no significant difference in mean initial diameter of the largest oocytes (control $=164 \pm 82 \mu \mathrm{m}$, rGthtreated $=172 \pm 72 \mu \mathrm{m}$ ). Although some females had started vitellogenic growth, at week 0 the ovaries had principally PG oocytes, some cortical alveoli oocytes (SGca) with very few oocytes in early vitellogenesis and some atresia (Figs. 5C, 5D, 6A).

A

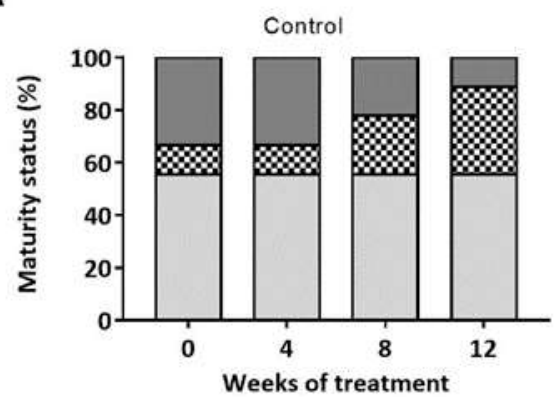

C

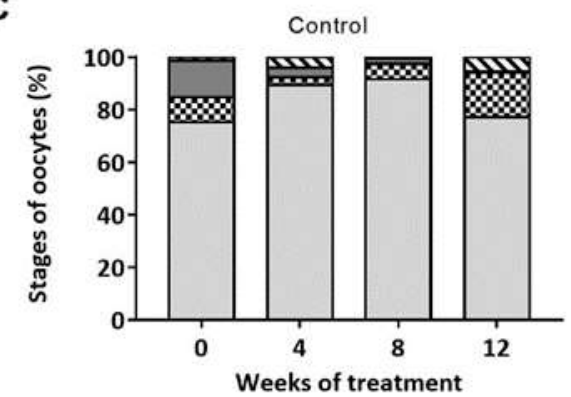

B

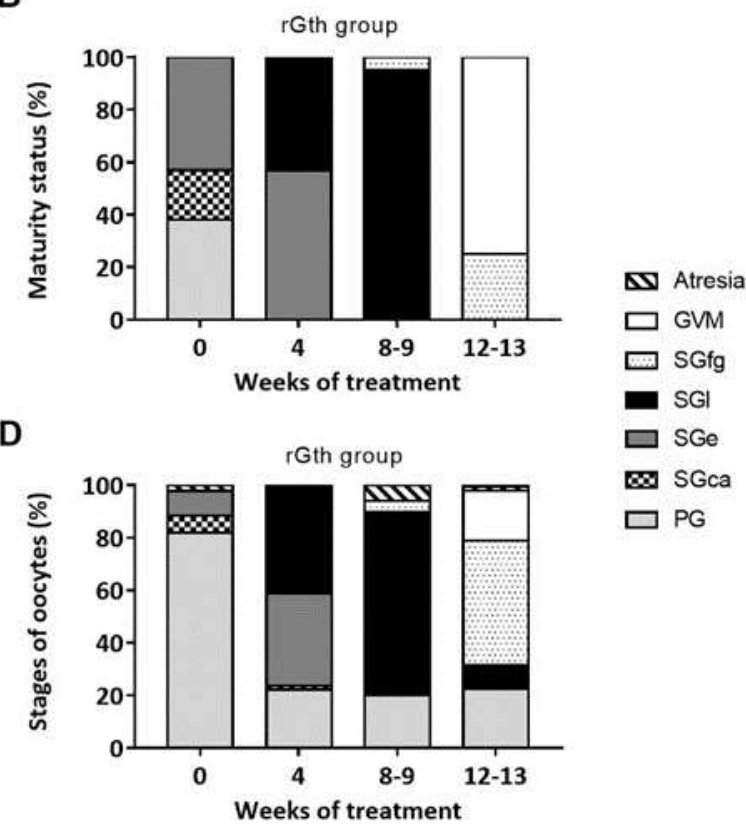

Figure 5. Percentage of females in different maturity stages of gonadal development in control (A) and rGth-treated group (B), and evolution of percentage frequency of oocyte developmental stages observed in control (C) and rGth-treated group (D) in different weeks of the experimental period. The maturity status of females was determined by the most advanced oocyte stage present in the samples. To calculate the percentage of each oocyte stage, a total of 50 random oocytes per female were classified and proportions were estimated. Each bar section represents the mean percentage of oocytes per stage from females for each week. PG, primary growth oocyte; SGca, cortical alveoli step; SGe, early secondary growth; SGl, mid- to late secondary growth oocyte (> $400 \mu \mathrm{m})$; SGfg, full-grown secondary-growth oocytes; GVM, initial germinal vesicle migration.

448 Previtellogenic females at PG from the control group did not show further development during the experiment (Fig 5A, 6D). The number of early-vitellogenic females in the control group decreased during the experiment, concomitantly there was an increase in the occurrence of follicular atresia (Fig. 5A, 5C). In addition, no significant differences in oocyte diameter were observed amongst weeks in the control group (Fig 4A). On the other hand, the hormonal treatment induced a significant $(\mathrm{P}<0.001)$ growth of oocyte diameter. The rGth-treated group showed a significant weekly increase in oocyte diameter $(\mathrm{P}<0.001)$ (Fig 4A) and by the fourth week of treatment all $(100 \%)$ females had progressed to vitellogenesis (Fig 5B). At this point, a clear clutch of vitellogenic oocytes 
bioRxiv preprint doi: https://doi.org/10.1101/2021.09.29.462352; this version posted October 1, 2021. The copyright holder for this preprint (which was not certified by peer review) is the author/funder, who has granted bioRxiv a license to display the preprint in perpetuity. It is made available under aCC-BY-NC-ND 4.0 International license.

was the most abundant in the ovaries (Fig 5D, 6B). From the sixth week onwards, different females completed oocyte growth (Fig 6C) with the majority completing gonadal development in week 12 and 13. To define the pattern of oocyte growth in the rGth-group, oocytes were aligned from the completion of vitellogenic growth and the growth was represented by a second order polynomial (quadratic) equation $y=113.9+$ $46253.62 \mathrm{x}-1.234 \mathrm{x}^{2}\left(\mathrm{R}^{2}=0.9625\right)$ (Fig 4B). A greater increase in oocyte diameter was observed between weeks (injections) in earlier stages, with $\sim 50 \mu \mathrm{m}$ per week, while approximately three weeks (injections) was required to grow the last $50 \mu \mathrm{m}$ to complete vitellogenic growth. Once calculated the oocyte volume $\left(V=4 / 3 \pi r^{3}\right)$, conversely, showed a greater weekly increase (more than 5 times greater) in the later stages of development compared to the early stages.

468 Concerning $\mathrm{E}_{2}$ levels, no significant differences were observed between control and treated group at the beginning of the experiment $\left(0.67 \pm 0.71 \mathrm{ng} \mathrm{mL}^{-1}\right.$ and $0.68 \pm 0.46 \mathrm{ng}$ $\mathrm{mL}^{-1}$, respectively), whereas a significant increase $(\mathrm{P}<0.001)$ was observed when the treated group completed vitellogenic growth $\left(1.53 \pm 0.70 \mathrm{ng} \mathrm{mL} \mathrm{m}^{-1}\right)$ in comparison with no changes in controls $\left(0.52 \pm 0.25 \mathrm{ng} \mathrm{mL}^{-1}\right)$ at the end of the experiment.
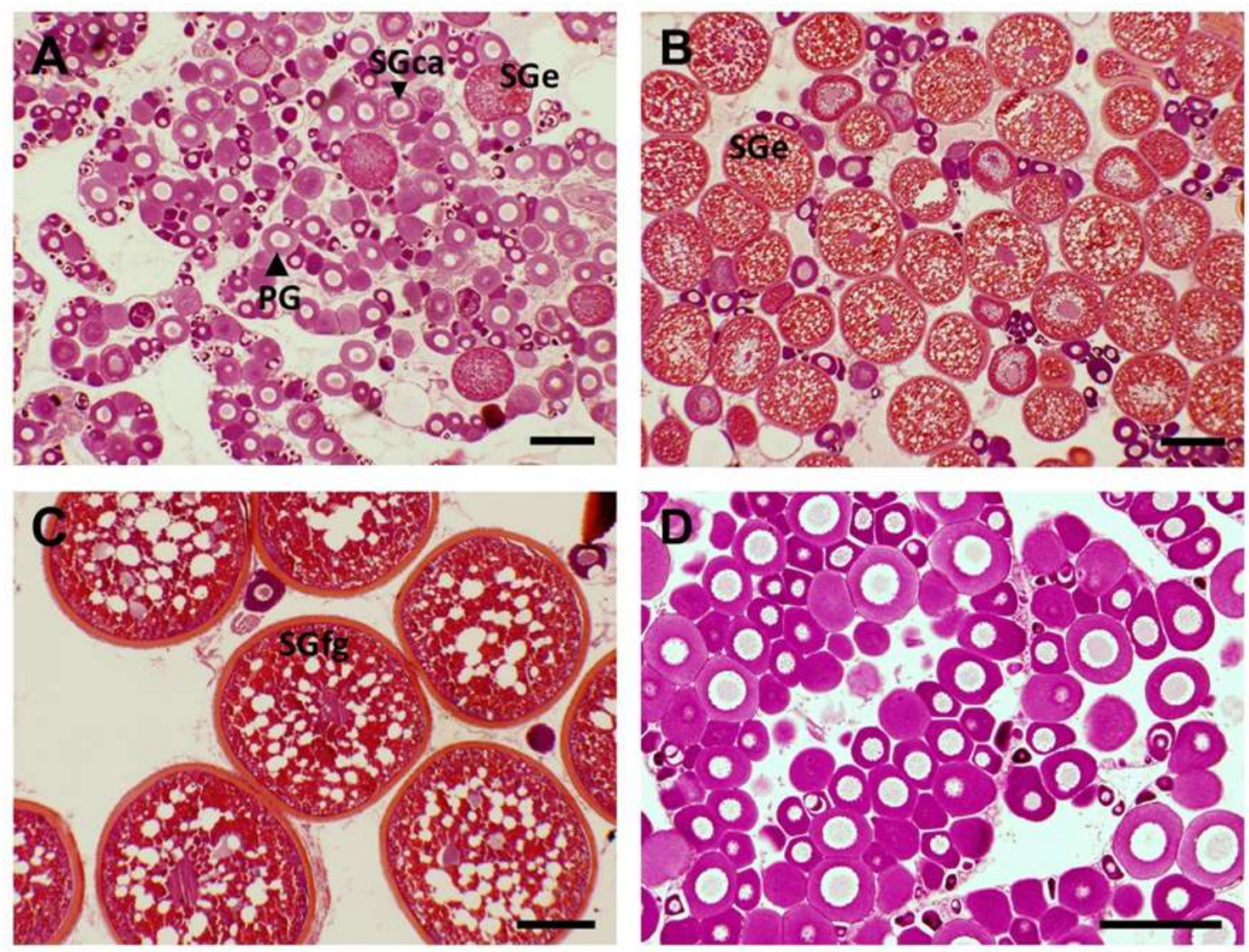

Figure 6. Histological photographs of representative ovarian biopsies from flathead grey mullet females (Mugil cephalus) during the experimental period. (A) A female in early-vitellogenesis (SGe) with mainly primary growth oocytes, some cortical alveoli stage (SGca) and only a small percentage of oocytes in SGe at the beginning of the experiment, (B) a female in SGe after rFsh treatment with a clear clutch of oocytes recruited into vitellogenesis, (C) a rGth-treated female with full-grown oocytes (SGfg), and (D) a control female in previtellogenesis by the end of the experimental period. Scale bar: $200 \mu \mathrm{m}$. 
bioRxiv preprint doi: https://doi.org/10.1101/2021.09.29.462352; this version posted October 1, 2021. The copyright holder for this preprint (which was not certified by peer review) is the author/funder, who has granted bioRxiv a license to display the preprint in perpetuity. It is made available under aCC-BY-NC-ND 4.0 International license.

482

484

\section{A}

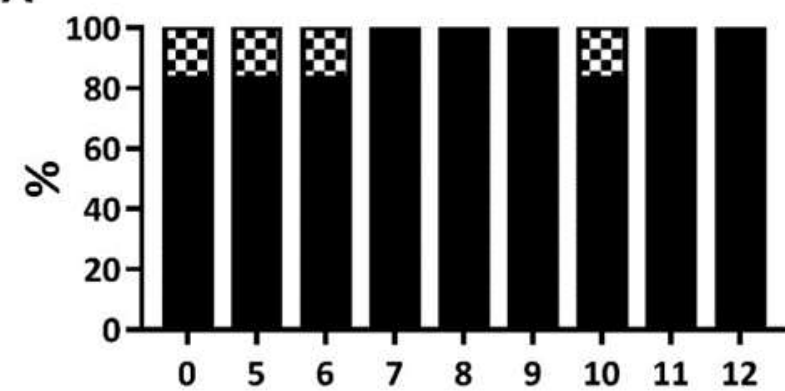

B

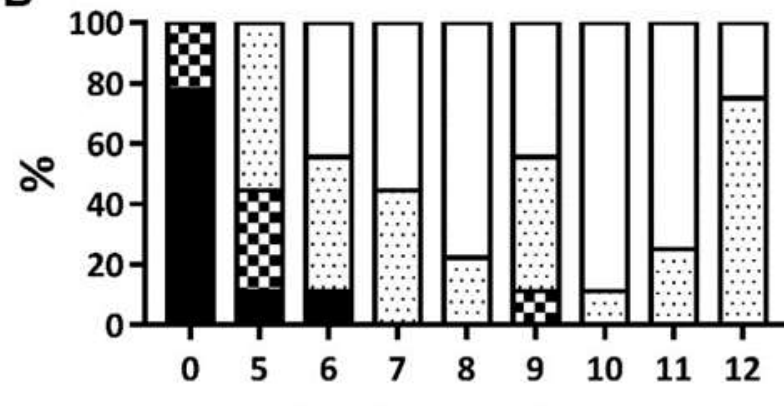

- No milt

$\mathbf{m}$ Traces of viscous milt

F. Fluent white milt

$\square$ Very fluent white milt

Number of weeks of treatment

494

Figure 7. Percentage of no spermiating and different degrees of spermiating males in (A) control (n $=6)$ and $(B)$ rGth-treated group $(n=9)$ during the males' treatment period. Males were classified as no milt (index 0), traces of viscous milt from which no sample could be obtained (index 1), fluent white milt (index 2) and very fluent white milt (index 3). Data from Group $1(\mathrm{n}=4$ rGth-treated males, $\mathrm{n}=3$ control) from the first application (week 0) to the last checking (week 12) was combined with data from Group 2 ( $n=5$ rGth-treated males, $n=3$ control) from week 0 to 10 in order to present the results.

The histological evaluation of the testes from two fish in which no milt was obtained after abdominal pressure at the beginning of the experiment, showed that one male presented only SPG within the seminiferous tubules, while the other male presented many SPG and some SPC, SPD and SPZ, but many tubules did not have the central lumen formed and those that had, presented very few spermatozoa (Fig 8A, B). During the experimental period, males in the control group did not produce fluent milt and only the same one male out of six $(17 \%)$ produced a small drop of viscous milt within different weeks. 

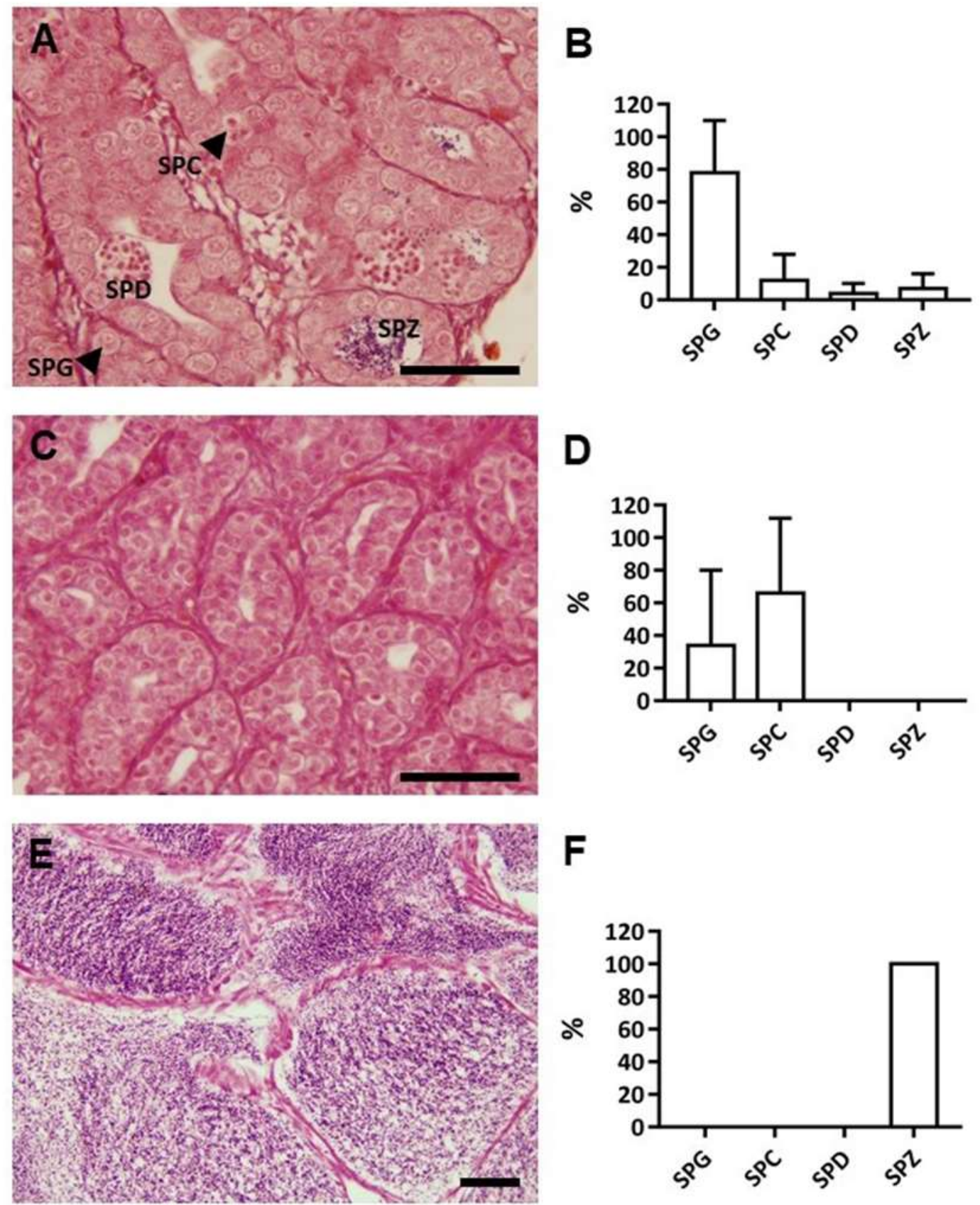

Figure 8. Histological sections of testis and the percentages of the spermatogenesis developmental

stages at the beginning of the study $(\mathrm{A}$ and $\mathrm{B}, \mathrm{n}=2)$ and at the end of the experimental period in control group ( $\mathrm{C}$ and $\mathrm{D}, \mathrm{n}=2)$ and $\mathrm{rGth}$-treated group ( $\mathrm{E}$ and $\mathrm{F}, \mathrm{n}=2)$. SPG, Spermatogonia; SPC, Spermatocyte; SPD, Spermatid; SPZ, Spermatozoa. Scale bars $=50 \mu \mathrm{m}$.

514 At the end of the experiment, the testis from two control males - the male that in previous weeks presented viscous milt and one male that never had milt - contained tubules with

516 a higher number of SPC than the initial situation, but there was no presence of SPD or SPZ (Fig 8C, D). In contrast, running males with fluent white milt were observed in the 518 rGth-group. After five weeks of treatment (three weeks of $\mathrm{rFsh}$ treatment and two weeks of combined rFsh and rLh treatment) eight out of nine (89\%) males presented milt; either 520 viscous traces (33\%) or fluent milt (56\%) (Fig 7). With the application of rLh, the number of males with fluent milt increased. By seven weeks, $100 \%$ of the males were 
522 spermiating with fluent milt and males maintained fluent milt until the end of experiment (week 12), with the exception of week 9 when one male produced viscous milt. However, 524 after the application of rFsh in Group 1 and continuing the rLh treatment in Group 2, fluent milt was produced again in the following week. In clear contrast to the control 526 males, in the histology from two rGth treated males at the end of the experiment, the sperm ducts of the rGth-group were completely filled with spermatozoa (Fig 8E, F) and

528 sperm volumes ranged from 0.25 to $2.89 \mathrm{~mL}$. In addition, GSI values reflected the growth of the testis with rGths treated males having significantly higher $(\mathrm{P}=0.026)$ GSI 530 compared to control group at the end of the experiment. Males before the hormonal treatment $(n=2)$ and control males at the end of the treatment $(n=2)$ showed thin 532 undeveloped testes with GSI of $0.10 \pm 0.05 \%$ and $0.06 \pm 0.01 \%$, respectively, while rGth-treated males at the end of the experiment $(n=2)$ presented well developed white 534 testes with $5.35 \pm 1.25 \%$ GSI. Taken together, males with sperm index 0 and 1 had germ cells predominantly at stages of SPG and SPC in undeveloped testes (GSI $\lesssim 0.1$ ) and the 536 rGth treatments induced testes growth (GSI $5.35 \pm 1.25 \%$ ) and development of germ cells to complete spermatogenesis and provide testes full of spermatozoa and fluent 538 spermiation (index 2 and 3).

In regard of steroid changes, rGths treatment had a significant effect in the increase of 11540 KT levels $(\mathrm{P}<0.001)$ compared to the control group (Fig 9) that was maintained without significant changes. In the rGths-group, increasing values of 11-KT were obtained within 542 the course of the experiment coinciding with the availability of spermiating males, with the maximum at eight weeks and a decrease afterwards.

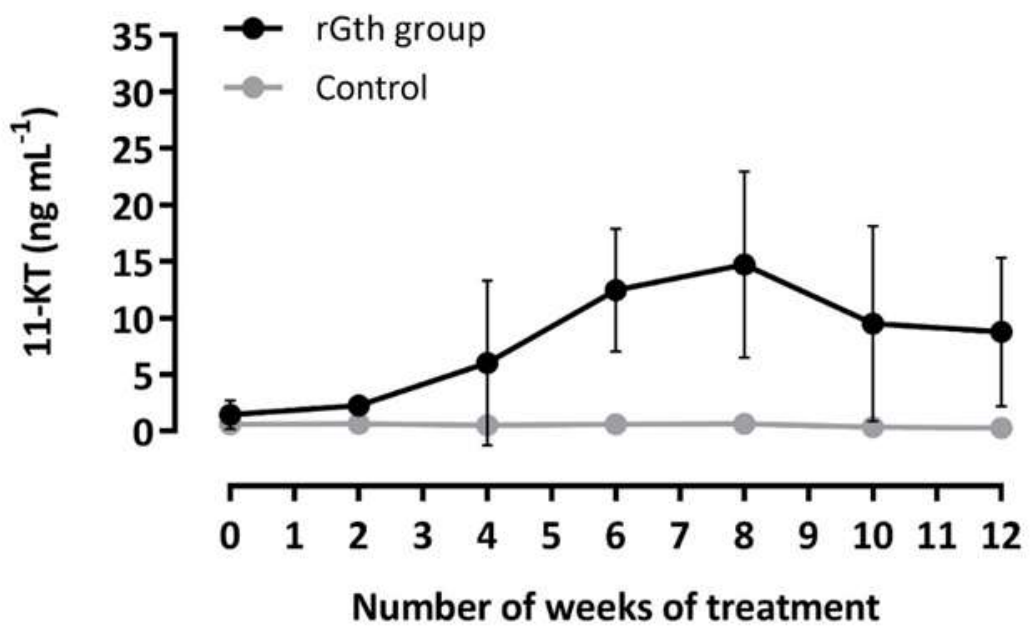

546 Figure 9. Effect of rFsh and rLh treatment (rGth group) and saline (control) on 11-ketotestosterone (11-KT) levels (mean \pm SD) in the flathead grey mullet (Mugil cephalus). Data from Group $1(n=4$ 548 rGth-treated males, $\mathrm{n}=3$ control) from the first application (week 0) to the last checking (week 12) was combined with data from Group 2 ( $n=5$ rGth-treated males, $n=3$ control) from week 0 to 10 in order to 550 present the results. Two-way RM ANOVA showed a significant effect of the rGths treatment on the production of 11-KT $(\mathrm{P}<0.001)$.

552

Regarding sperm quality, on the day of collection (0h), the sperm diluted 1:10 in Marine 554 freeze had the following mean characteristics: motility of $58 \pm 22 \%$, head size of $13 \pm 5$ $\mu \mathrm{m}^{2}, 107 \pm 24 \mu \mathrm{m} \mathrm{s}^{-1} \mathrm{VCL}, 92 \pm 29 \mu \mathrm{m} \mathrm{s}^{-1} \mathrm{VAP}, 70 \pm 31 \mu \mathrm{m} \mathrm{s}^{-1} \mathrm{VSL}, 67 \pm 12 \%$ STR, 57 
$556 \pm 16 \%$ LIN, and $79 \pm 11 \%$ WOB. Whilst $20 \pm 16 \%$ of the motile spermatozoan were fast progressive that had velocity of $149 \pm 17 \mu \mathrm{m} \mathrm{s}^{-1} \mathrm{VCL}, 140 \pm 20 \mu \mathrm{m} \mathrm{s}^{-1} \mathrm{VAP}, 129 \pm$ $55821 \mu \mathrm{m} \mathrm{s}^{-1}$ VSL, $92 \pm 2 \%$ STR, $86 \pm 7 \%$ LIN, and $93 \pm 6 \%$ WOB. The variation amongst the nine males was wide with $\%$ sperm motility ranging from 19 to $89 \%$. The mean 560 concentration was $7.59 \times 10^{10}$ spermatozoa $\mathrm{mL}^{-1}$ or $15.56 \times 10^{10}$ spermatozoa $\mathrm{kg}^{-1}$. The sperm diluted in Marine Freeze ${ }^{\circledR}$ had significantly higher motility than undiluted sperm

562 on the day of collection $(0 \mathrm{~h})$ and $48 \mathrm{~h}$ after collection (Fig 10). The motility of undiluted sperm decreased significantly from day 0 to $48 \mathrm{~h}$ after collection, compared to diluted

564 sperm that maintained similar motility. The sperm collected and diluted in Marine Freeze ${ }^{\circledR}$ at the end of the experiment (week 13) maintained similar motility for 6 days of storage at $4^{\circ} \mathrm{C}$ (tested days $0,1,2,4$ and 6) with variation from $41.1 \pm 20.0 \%$ to $70.2 \pm$ $17.3 \%$ before decreasing significantly from day $4(70.2 \pm 17.3 \%)$ to day $8(11.7 \pm 5.1 \%)$, whilst day 6 was intermediate $(41.1 \pm 20.0 \%)$.

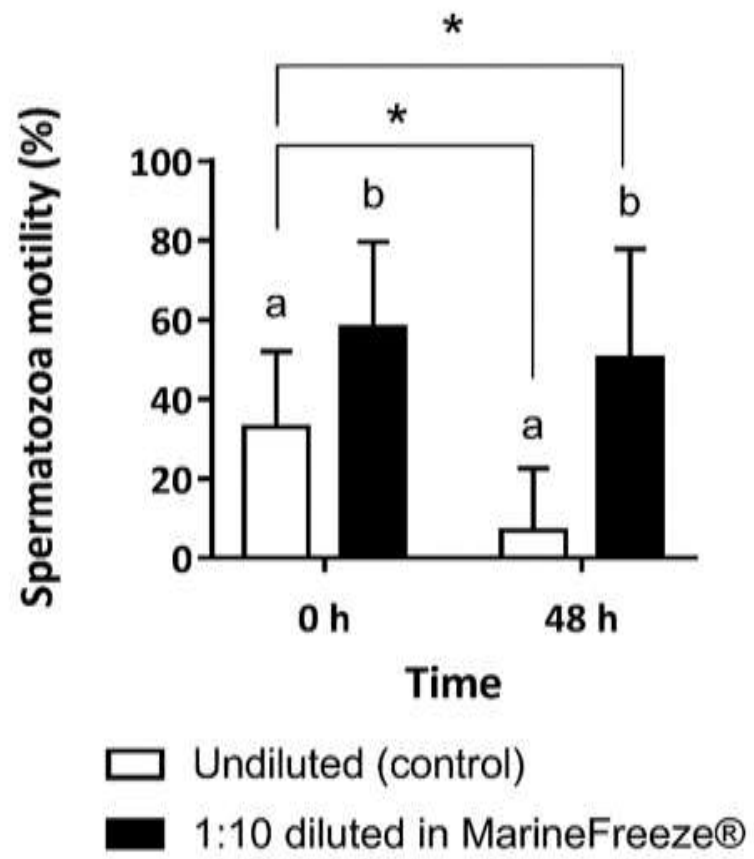

Figure 10. Percentage motility of sperm samples collected from rGth-treated males at the end of the experimental period (week 10 and 13). A two-way RM ANOVA was performed followed by the HolmSidak post hoc test with males as subjects, time of storage ( 0 or $48 \mathrm{~h}$ ) and sample dilution (undiluted or 1:10 diluted in Marine Freeze $($ ) as the independent variables, and percentage motility as the dependent variables. Different letters indicate significant differences between undiluted and diluted samples within the same time of evaluation, while asterisks show significant differences between evaluation time.

\subsection{Oocyte final maturation and spawning induction}

Females of flathead grey mullet that had completed vitellogenic growth — available only 580 from the rGth-group - were selected for spawning induction following three different treatments. Gonad samples were examined before the priming injections and after 24:05 $582 \pm 0: 40 \mathrm{~h}$, just prior to the resolving doses. Ovaries from chosen females were composed by SGfg with a mean size of $603 \pm 8 \mu \mathrm{m}$ and the $76 \%$ (16 of 21) of the females presented

$58417 \pm 23 \%$ of oocytes that had already initiated $\mathrm{OM}$ with the migration of germinal vesicle 
(Fig 5D); the nucleus had moved off-center and there was a small degree of fusion of yolk granules and lipid droplets, but with no single large yolk mass. No significant differences in oocyte diameter or the percentage of OM were found between the females that received different spawning treatments. After the priming injections $(24 \mathrm{~h}), 100 \%$ of the females that received $\mathrm{rLh}$ had entered into OM with most of the oocytes $(96 \pm 9 \%)$ in late GVM with yolk coalescence (Fig 11). Meanwhile, those that received $\mathrm{P}_{4}$ did not show a significant increase in GVM percentage $(35 \pm 35 \%)$ respect to initial stage $(12 \pm 5 \%)$ thereby showing that most of the oocytes were retained at the secondary growth stage.

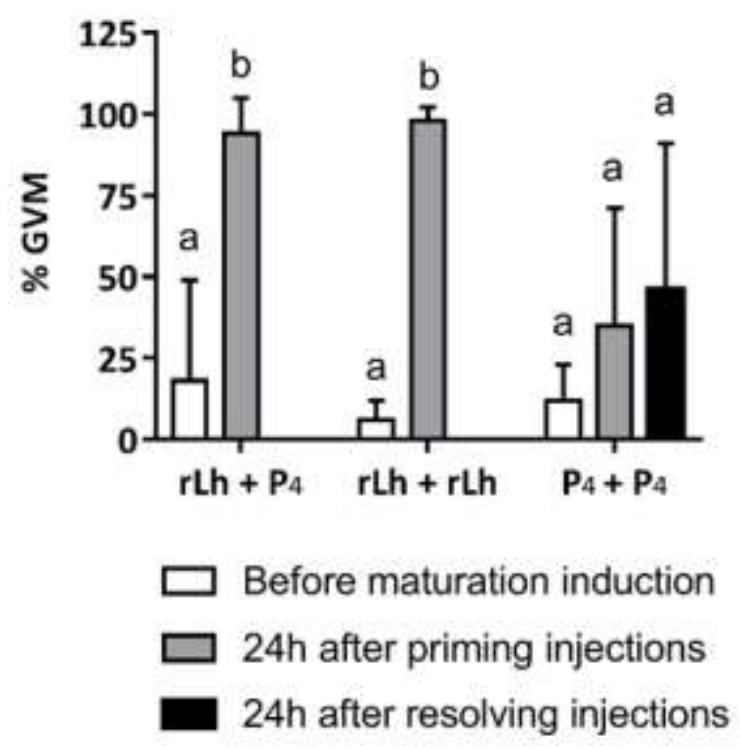

594

Figure 11. Percentage of oocytes at maturation stage (OM) with germinal vesicle migration (GVM) before $O M$ induction, $24 \mathrm{~h}$ after the priming injections and $24 \mathrm{~h}$ after the resolving injections. Treatments applied to induce $\mathrm{OM}$ and spawning were (i) priming $30 \mu \mathrm{g} \mathrm{kg}^{-1} \mathrm{rLh}$ and $40 \mathrm{mg} \mathrm{kg}^{-1}$ resolving 598 Progesterone $\left(\mathrm{P}_{4}\right)$, (ii) $30 \mu \mathrm{g} \mathrm{kg}^{-1} \mathrm{rLh}$ as priming and resolving injections or (iii) $40 \mathrm{mg} \mathrm{kg}^{-1} \mathrm{P}_{4}$ as priming and resolving injections given 24:05 \pm 0:40 h apart. Different letters indicate significant differences at different timing of the inductions within a same treatment following One-way RM ANOVA.

602 The proportions of females that ovulated or spawned did not vary between the initial maturity status of females at the beginning of the experiment $\left(\chi^{2}=1.150 ; \mathrm{gl}=2 ; \mathrm{P}=0.563\right.$

$\left.6040.001 ; \chi^{2}=2.149 ; \mathrm{gl}=2 ; \mathrm{P}=0.342\right)$. In the $\mathrm{rLh}+\mathrm{P}_{4}$ group, $100 \%$ of the females ovulated and eight out of nine females (89\%) spawned in the tank 16:36 $\pm 1: 56$ after the resolving 606 injection. In the $\mathrm{rLh}+\mathrm{rLh}$ group, $100 \%$ of the females $(\mathrm{n}=6)$ ovulated and spawned 16:51 $\pm 2: 22 \mathrm{~h}$ after the resolving injection. Meanwhile, three out of six fish $(50 \%)$ under

$608 \mathrm{P}_{4}+\mathrm{P}_{4}$ treatment ovulated but only one (17\%) actually liberated some eggs (177,667 eggs) $24: 30 \mathrm{~h}$ from the administration of the resolving dose. The average number of eggs

610 spawned and female fecundity for each hormone treatment were similar (Table 1). Those females that did not ovulate in the $\mathrm{P}_{4}$ treatment group, did not show a significant increase 612 in $\mathrm{OM}$ after the second $\mathrm{P}_{4}$ (Fig 11). The eggs from the females that ovulated and did not spawn were stripped by applying gentle abdominal pressure to liberate all ovulated eggs

614 from the female. The stripped eggs did not have the appearance of viable eggs and formed a dense globular mass with almost no ovarian fluid. 
616 The in vitro incubation of oocytes that had initiated $\mathrm{OM}$ confirmed the in vivo ovulation and spawning. The highest percentages of ovulation (> 50\%) were obtained from oocytes 618 treated with $\mathrm{P}_{4}\left(4000,1000,500\right.$ and $50 \mathrm{ng} \mathrm{kg}^{-1}$ ) or $100 \mathrm{ng} \mathrm{kg}^{-1}$ of rLh (Fig 12). All oocytes treated with $\mathrm{P}_{4}$ and oocytes treated with 400,200 and $100 \mathrm{ng} \mathrm{kg}^{-1}$ of $\mathrm{rLh}$ had significantly

620 (P < 0.05) higher percentages $(>34 \%)$ of ovulation than untreated oocytes (control) and oocytes treated with $\mathrm{rFsh}$ or $10 \mathrm{ng} \mathrm{kg}^{-1}$ of $\mathrm{rLh}(<8 \%)$. Oocytes treated with $50 \mathrm{ng} \mathrm{kg}^{-1}$ of $622 \mathrm{rLh}$ had a percentage of ovulation $(21.3 \pm 18.5 \%)$ that was intermediate between the highest and lowest ovulation groups.

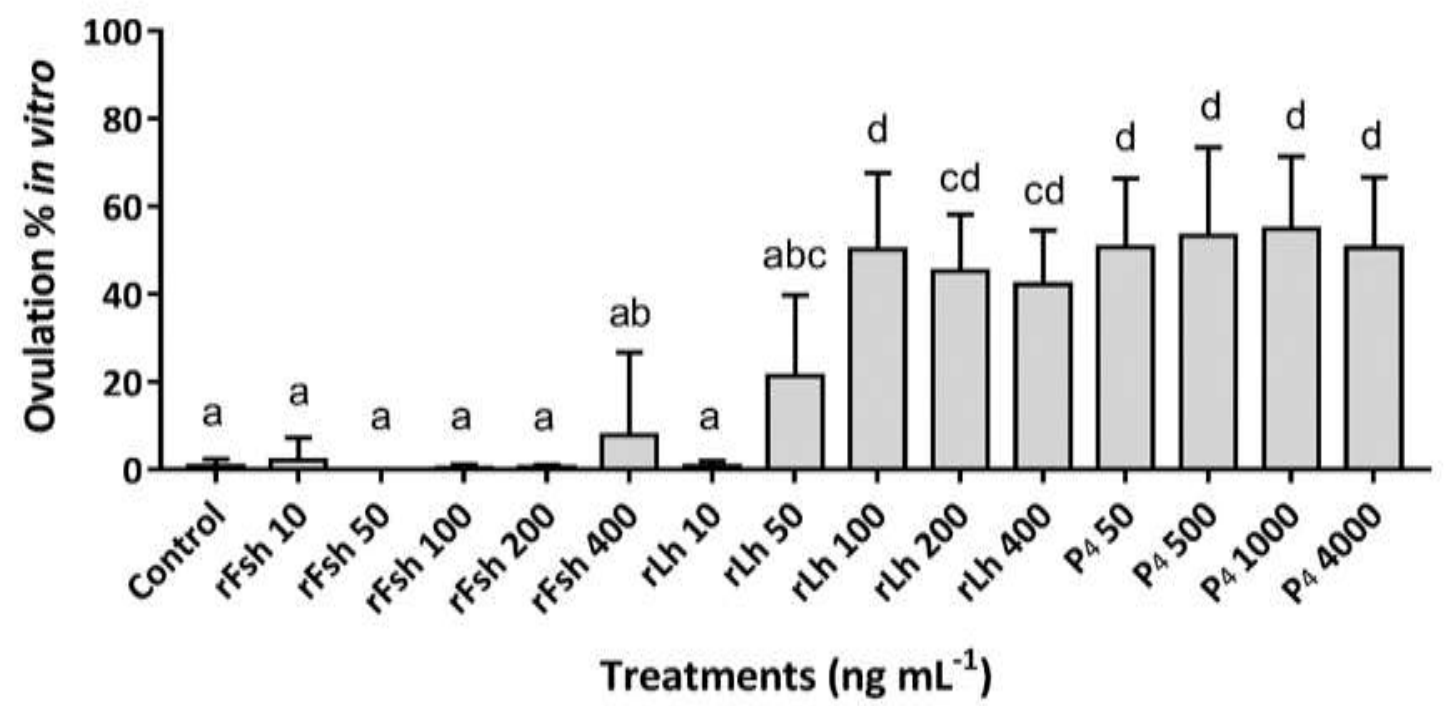

Figure 12. In vitro percentage of ovulation (mean $\pm \mathrm{SD}$ ) of oocytes in $\mathrm{OM}$ with different effectors, doses and combinations of efectors and doses. Statistical differences between treatments were examined by a one-way repeated measures ANOVA with individual females as subjects ( 3 replicates per individual, 6 individuals $\mathrm{n}=18$ wells per hormone concentration).

\subsection{Egg and larval quality}

632 No significant differences were found in latency, egg production and quality parameters; fecundity, percentages of fertilization, embryo survival or hatching, in those females that received $\mathrm{rLh}$ as priming dose and either $\mathrm{rLh}$ or $\mathrm{P}_{4}$ as resolving injections (Table 1). There were also no differences between females that were at different maturity stage at the beginning of the experiment. Mean total fecundity was 1,738,798 $\pm 868,950$ eggs per female (relative fecundity was 1,245,600 $\pm 552,117$ eggs $\mathrm{kg}^{-1}$ bw) with $54 \pm 21 \%$

638 fertilization. On the contrary, spawned eggs from one female that received $\mathrm{P}_{4}+\mathrm{P}_{4}$, were not fertilised ( $0 \%$ fertilization).

640 No differences were observed in egg and larval quality between $\mathrm{rLh}+\mathrm{rLh}$ and $\mathrm{rLh}+\mathrm{P}_{4}$ groups. The embryo survival and hatching percentages were $64 \pm 22 \%$ and $57 \pm 24 \%$, respectively. Hatching in EIA 96-well plates was $96 \pm 3 \%$. Eggs with an embryo measured $0.83 \pm 0.02 \mathrm{~mm}$ in diameter (Fig 13A) and larvae length at hatching was 1.86 $644 \pm 0.14 \mathrm{~mm}$ total length (TL). Larval survival rate in the 96 -well plates at $21{ }^{\circ} \mathrm{C}$ was $85 \pm$ $18 \%$ at $2 \mathrm{dhp}, 67 \pm 18 \%$ at $5 \mathrm{dhp}, 55 \pm 17 \%$ at $9 \mathrm{dph}$ and decreased until $8 \pm 11 \%$ on $12 \mathrm{dph}$. By $14 \mathrm{dph}$, all larvae were dead. 
bioRxiv preprint doi: https://doi.org/10.1101/2021.09.29.462352; this version posted October 1, 2021. The copyright holder for this preprint (which was not certified by peer review) is the author/funder, who has granted bioRxiv a license to display the preprint in perpetuity. It is made available under aCC-BY-NC-ND 4.0 International license.
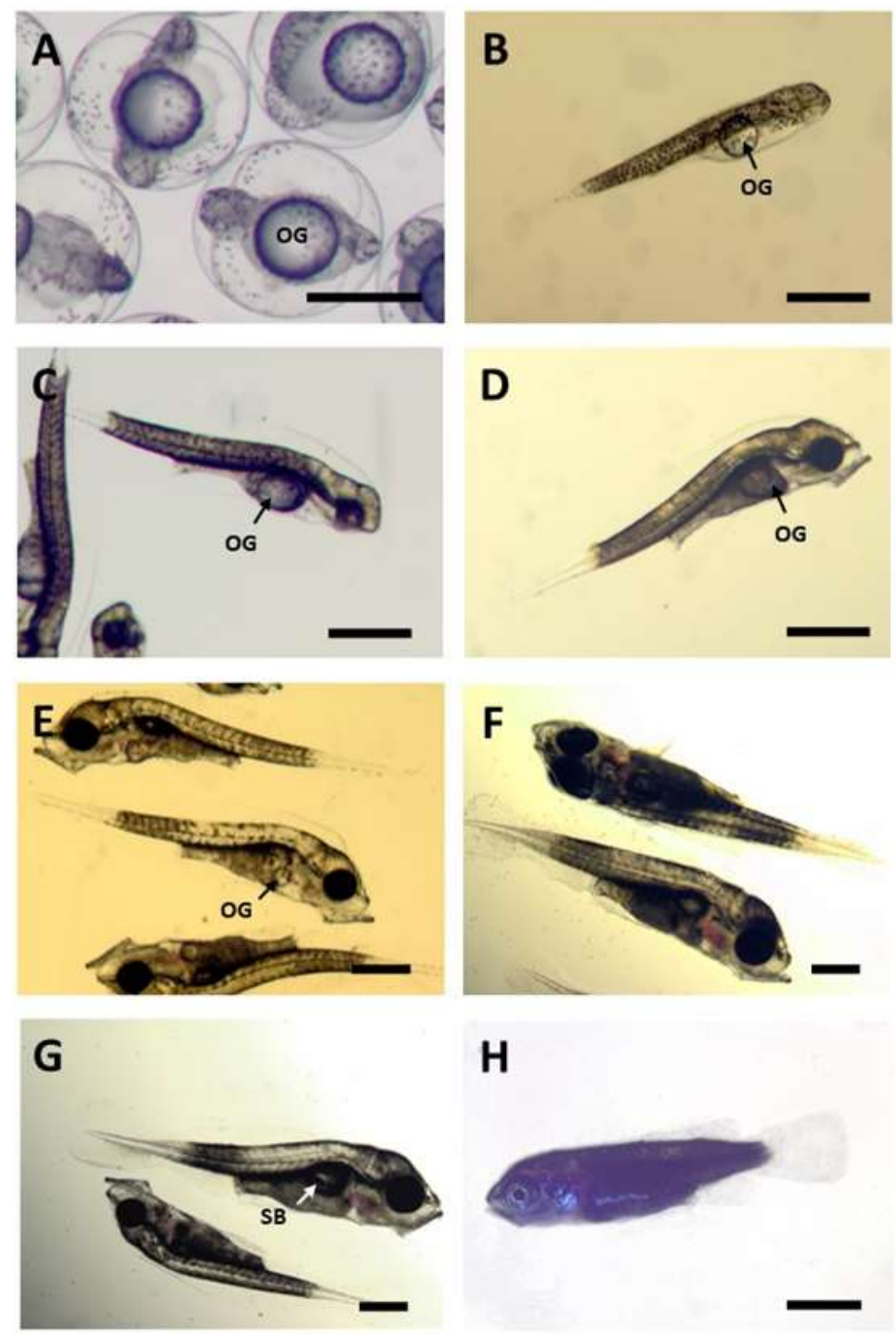

H
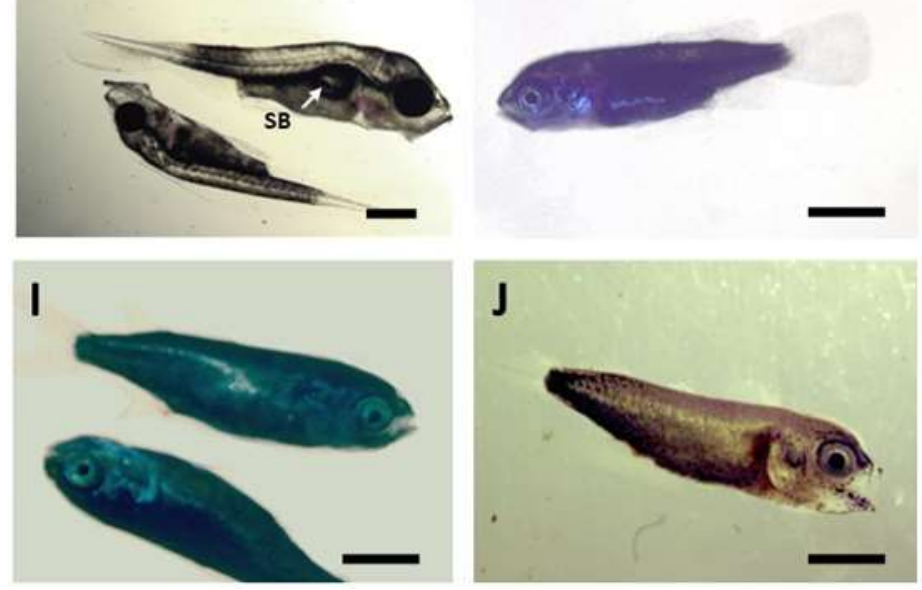

648 Figure 13. Mugil cephalus embryos, larvae, post-larval and juvenile stages. (A) Embryo with head region formed and dark pigment covering almost all the body and the oil globule (OG), (B) newly hatched 650 larvae, (C) larvae at $2 \mathrm{dph}$ with eyes already pigmented, (D) larvae at $3 \mathrm{dph}$ with the mouth parts completely formed and functional, (E) larvae at $9 \mathrm{dph}$ with the oil globule still present, (F) larvae at $19 \mathrm{dph}$ with the oil

652 globule completely absorbed and $(\mathrm{G})$ with a hyperinflated swim bladder $(\mathrm{SB}),(\mathrm{H})$ post-larvae at $32 \mathrm{dph}$, (I) post-larvae at $37 \mathrm{dph}$, (I) juvenile at $39 \mathrm{dph}$. Scale bar: $500 \mu \mathrm{m}$ in A, B, C, D, E, F and G, $1 \mathrm{~mm}$ in H, I, and $\mathrm{J}$.

656 Larvae used for the preliminary larval culture trial measured $2.1 \pm 0.05 \mathrm{~mm} \mathrm{TL}$ at hatching showing a homogeneous yolk mass with a round oil droplet at the posterior part 658 of the yolk sac (Fig 13B). The eyes started to be pigmented between days 1 and $2 \mathrm{dph}$. Upper and lower jaws were well-developed and the mouth was open from 3 dph $(2.93 \pm$

$6600.08 \mathrm{~mm}$ TL, Figs 13C, 14) when the larvae had consumed most of the yolk reserves and only the oil globule remained (Fig 13D). The pre-flexion stage lasted from 4 to $19 \mathrm{dph}$ 
662 with yolk and oil droplet completely absorbed $(11 \mathrm{dph})$. Swim bladder formation started around day 4 - 6 (2.9 - 3.11 mm TL, Fig 14) visible ventrally beneath the notochord. The

664 swimming activity of the larvae increased during the formation and enlargement of the swim bladder although several larvae either swam at the bottom of the tank, or remained

666 floating in the water surface without moving and/or feeding on rotifers due to a hyperinflation of the swim bladder (Fig 13G). Most of these larvae died and, in order to

668 reduce this mortality, light intensity was reduced to 500 lux from 9 dph until the end of the rearing trial. The tail flexion was completed when the larvae reached $3.7 \mathrm{~mm}$ length 670 whereas the post-flexion stage was extended during several days ( 20 - $30 \mathrm{dph}, 4.3-5.3$ $\mathrm{mm}$ TL, Fig 14) until the caudal fin and fork were completed. At the end of the trial (day 672 39) all the fish looked like adult individuals and were considered juveniles (Fig 13J). Development of Mugil cephalus larvae and post-larval stages to juvenile are shown in Figs 13 and 14.

\section{Discussion}

Flathead grey mullet (Mugil cephalus) held in intensive captive conditions experience reproductive dysfunctions early in the maturation process and both males and females needed to be assisted to induce vitellogenesis, oocyte maturation, ovulation, enhance

680 spermatogenesis, spermiation and spawning. The present study shows that $\mathrm{rFsh}$ and $\mathrm{rLh}$ can be used as a reliable method to induce and complete oogenesis from previtellogenesis,

682 produce milt and induce spontaneous voluntary tank spawning, in 100\% of experimental fish to provide viable, good quality eggs and larvae.

684 Observing the ovarian developmental stage at the start of the experiment, a range of dysfunctions were found in females; fish were arrested at stages that ranged from 686 previtellogenesis as in Ramos-Júdez et al. (2021) through to early vitellogenesis as reported in other Mediterranean areas (Aizen et al., 2005). Nevertheless, in the present

688 study, the ovaries of the early-vitellogenic females at the beginning of the experiment had few vitellogenic oocytes that were not distributed homogeneously and actually

690 previtellogenic oocytes were the most abundant stage of development in all females. The females that received the rFsh and rLh treatment, as previously described by Ramos-Júdez

692 et al. (2021), showed a uniform clutch of abundant oocytes recruited into vitellogenesis and followed the typical ovarian development in this species. Mugil cephalus has group

694 synchronous ovary development with one clutch of oocytes maturing annually following a single spawning episode (Kumar et al., 2015). The rGth hormonal administration was $696100 \%$ successful in inducing vitellogenesis from previtellogenesis (12 of 12 females) and early vitellogenesis (9 of 9 females) to complete vitellogenic growth. In comparison,

698 control females that were at early vitellogenesis remained without advances in gonad development during the experiment and presented atresia, which may indicate a lack of

700 stimulation of the vitellogenic oocytes to develop further (Lubzens et al., 2010). Previtellogenic control females did not show further development. This observation is in

702 clear contrast with Aizen et al. (2005), in which up to $20 \%$ of control females developed mature oocytes without hormonal stimulation. The completion of vitellogenesis in rGth-

704 treated females was accompanied by an increase in plasma $\mathrm{E}_{2}$ levels, that was not observed in controls, showing the gonadotropic stimulation of the ovary by rGths. Ramos-

706 Júdez et al. (2021), using the same rGths, obtained an almost identical result with an increase in plasma $\mathrm{E}_{2}$ levels and eight out of nine (89\%) of treated females completing oogenesis. 
The rGth treatment in males induced and enhanced spermatogenesis and spermiation as $100 \%$ of treated males produced fluent milt for 8 weeks or more. In comparison, control group males remained with no fluent sperm during the experiment. The histological

712 examination of males at different stages of spermiation showed that initial or control captive males that presented no sperm or a little drop of viscous sperm had undeveloped 714 testes with a low GSI ( $\lesssim 0.1 \%$ ), predominantly SPG and SPC and few or no SPD or SPZ. In comparison, the histological examination showed rGth-treated males had well

716 developed testes with a significantly higher GSI $(5.35 \pm 1.25 \%)$, that was 50 times higher than control males, and testes were filled entirely with SPZ and no SPG or SPC. Although

718 there was significant growth, some caution is perhaps required in extrapolating the histology from two fish to the other individuals in the control and rGth groups. Few males

720 were available and the $\mathrm{n}$ for histology was reduced to ensure sufficient males for rGth treatment and spawning. All the evidence indicates that the rGths have induced

722 spermatogenesis of large numbers of germ cells from early stages (SPG and SPC) through to SPZ. Clearly more work is required for confirmation of this rGth action and a specific

724 study on the direct effect of each rGth on testes development and in the pattern of administration has to be performed to consolidate conclusions. However, other studies,

726 as suggested in the present study, have successfully induced spermatogenesis with rGths, i.e. in sexually immature European eel (Peñaranda et al. 2018), immature Japanese eel

728 (Hayakawa et al., 2008; Kamei et al., 2006; Kobayashi et al., 2010) and mature Senegalese sole (Chauvigné et al., 2018, 2017). Peñaranda et al. (2018), represents a

730 specific study that tested different combinations in the application of homologous $\mathrm{rFsh}$ and rLh (produced by Rara Avis Biotec, S. L. as in the present study) in immature

732 European eel that lead to different testis development including different degrees of spermiation. The biological effects of rGths on males were also evaluated through plasma

734 11-KT levels, which is the major androgen responsible for testicular development (Aizen et al., 2005; Chauvigné et al., 2012; Mañanós et al., 2009; Schulz et al., 2010). The rGth 736 treatment significantly increased the levels of 11-KT in the plasma of treated males compared to control males. The concentration of plasma 11-KT in treated males increased

738 gradually in response to $\mathrm{rFsh}$ and $\mathrm{rLh}$ application, as maturity progressed with the presence of sperm and the increased fluidity of milt obtained in all treated males from 5

740 weeks onwards. The levels of $11-\mathrm{KT}$ measured, from 0.1 to $28 \mathrm{ng} \mathrm{mL}^{-1}$, were in the range of levels previously measured in flathead grey mullet males treated with $17 \alpha-$

742 methyltestosterone implants to enhance spermatogenesis and spermiation (Aizen et al., 2005).

744 Higher quantities of fluent milt were obtained $(0.25$ to $2.89 \mathrm{~mL})$ in the present study compared to Ramos-Júdez et al. (2021) (max 0.25 mL). The increased sperm production

746 may be due to the different pattern and dosage of rGths administration, which included a longer period and higher doses for rLh. The quality of the sperm was variable amongst

748 the nine rGth-treated males with adequate mean sperm quality parameters of motility and velocity. The volume of sperm obtained was amongst the highest reported for wild mature

750 Mugil cephalus, such as 0.1 to $2 \mathrm{~mL}$ (Ramachandran and Natesan, 2016) and the concentration was two powers to ten $\left(10^{10}\right)$ higher than previously reported $\left(10^{8}\right)$

752 (Ramachandran and Natesan, 2016) indicating that a higher degree of dilution during spermiation, which is attributed to the action of Lh (Schulz and Miura, 2002), would be

754 desirable. The extender Marine Freeze ${ }^{\circledR}$ was effective to maintain sperm quality during 6 days of cold $4^{\circ} \mathrm{C}$ storage, which also indicated the sperm was of good quality.

756 From an applied point of view, male development was synchronised with the female's completion of vitellogenesis making them available for the spawning events. Selected 
males had fluid sperm and were administered either 12 or $24 \mu \mathrm{g} \mathrm{kg}^{-1} \mathrm{rLh}$ to stimulate spermiation and reproductive behaviour. Regarding females, three treatments were applied to induce oocyte maturation, ovulation and spawning. The application of $30 \mu \mathrm{g}$ $\mathrm{kg}^{-1} \mathrm{rLh}$ as priming injection induced oocyte maturation with the migration of the

762 germinal vesicle in all $100 \%$ of females when revised before the application of the resolving dose (24h after the priming dose). The following resolving injections of $40 \mathrm{mg}$ $\mathrm{kg}^{-1} \mathrm{P}_{4}$ or $30 \mu \mathrm{g} \mathrm{kg}^{-1} \mathrm{rLh}$ induced $100 \%$ of the fish to ovulate, and $89 \%$ ( $\mathrm{P}_{4}$ resolving) or $100 \%$ (rLh resolving) of fish to tank spawn, with a mean percentage fertilization of $54 \pm$ $21 \%$ indicating the success in the application of both treatments. The in vivo success of the resolving doses was confirmed by the success of both $\mathrm{P}_{4}$ and $\mathrm{rLh}$ to induce in vitro ovulation after the priming dose of rLh. The in vitro test indicated the importance of the selection of a correct rLh dose for the induction of ovulation, as the response of oocytes was different depending on the $\mathrm{rLh}$ concentration in the media. Otherwise, low $\mathrm{P}_{4}$ doses were as effective for inducing ovulation as high doses which suggests that a refinement in the $\mathrm{P}_{4}$ dose applied in vivo would be possible. On the contrary to females that received $\mathrm{rLh}$ as a priming injection, females that received priming $\mathrm{P}_{4}$ had not initiated $\mathrm{OM} 24 \mathrm{~h}$ after the priming dose. The $\mathrm{P}_{4}$ resolving dose had no effect on $50 \%$ of females, whilst the other $50 \%$ of the females ovulated, and from this, just one female (17\%) spawned eggs that had no fertilization. Although $\mathrm{P}_{4}$ as priming and resolving treatment did induce ovulation, all the maturation and ovulation process was concentrated in less than $24 \mathrm{~h}$ after the resolving dose was applied. In comparison, females that received $\mathrm{rLh}$ as priming completed OM and ovulation during 40:45 $\pm 2 \mathrm{~h}$ initiating $\mathrm{OM}$ after the priming dose and completing $\mathrm{OM}$, ovulation and spawning after the resolving dose. It is possible that ovulation was induced by the double $\mathrm{P}_{4}$ even though $\mathrm{OM}$ had not been induced, indicating the importance in this process of Lh or Lh-induced factors as previously indicated by Ramos-Júdez et al. (2021). In that study, only the females that received the highest 784 priming $\mathrm{rLh}$ dose $\left(30 \mu \mathrm{g} \mathrm{kg}^{-1}\right)$ proceeded to OM compared to females that received a lower priming rLh dose $\left(15 \mu \mathrm{g} \mathrm{kg}^{-1}\right)$, which did not develop to OM. Taken together, the 786 action of the hormones appear to confirm described roles (Lubzens et al., 2010; Mañanós et al., 2009) as high doses of rLh were required to induce oocyte maturation and either rLh or $\mathrm{P}_{4}$ were needed after the priming rLh dose to induce ovulation and spawning.

The two hormone treatments, $\mathrm{rLh}+\mathrm{rLh}$ and $\mathrm{rLh}+\mathrm{P}_{4}$, induced spontaneous tank spawning of large numbers of fertilised eggs. Therefore, the rGth treatment did not only induce gametogenesis development, but also the reproductive behaviour of both sexes to achieve

792 a successful courtship that led to spawning and successful fertilisation of liberated gametes. The presence of good quality males in the tank with fluent milt may also have

794 been a decisive factor for spawning success. Besides, a proper male to female sex ratio could also have been important. In the present study, male to female ratios of 2:1 or 3:1

796 were placed together and typical mating behaviour - swimming close to the female, pushing the abdomen with their head and body, ceasing to swim momentarily (Whitfield 798 et al., 2012) - was observed by males when females had swollen bellies. In addition, the data from the present study indicate that high-quality eggs up to $80 \%$ fertilization can be 800 obtained through the induction of oogenesis by rFsh and rLh in previtellogenic females. Retrieving good quality floating eggs from females that spawned with treated males 802 contrasts notably with the report by Ramos-Júdez et al. (2021) in which no spontaneous spawning was observed after priming $\mathrm{rLh}$ and resolving $\mathrm{P}_{4}$ spawning treatment. Ramos804 Júdez et al. (2021) did not observe spawning behaviour in rGth treated fish and, therefore, gametes were stripped and artificially fertilised to obtain $0.4 \%$ percentage fertilisation.

806 Therefore, the present study would suggest that other factors such as a delay in the stripping of the eggs coinciding with the process of egg overripening as stated in Ramos- 
808 Júdez et al. (2021) may have resulted in the low fertilization percentages in that study rather than the application of the rGth treatment per se.

810 Comparisons of spawning success (number of fish that spawned from total injected), fertilization rates and fecundities in other studies with flathead grey mullets are limited

812 owing to differences in methodology and initial gonadal development stage of individuals. A few studies have attempted to enhance vitellogenesis, such as

814 administration of $5 \mathrm{mg} \mathrm{kg}^{-1}$ Domperidone (Dom) or in combination with implants of 10 $\mu \mathrm{g} \mathrm{kg}^{-1}$ gonadotropin-releasing hormone agonist (GnRHa), in which lower rates of fully

816 mature females were obtained (50\% - 85\%) (Aizen et al., 2005). Many other studies worked with fully mature females and applied different treatments to induce oocyte 818 maturation and spawning. For example, Aizen et al. (2005) applied GnRHa (10 $\mathrm{g} \mathrm{kg} \mathrm{k}^{-1}$ priming, $20 \mu \mathrm{g} \mathrm{kg}^{-1}$ resolving) combined with Metoclopramide $\left(15 \mathrm{mg} \mathrm{kg}^{-1}\right.$ priming and 820 resolving), El-Gharabawy and Assem (2006) injected 20 to $70 \mathrm{mg} \mathrm{kg}^{-1}$ carp pituitary extract or 10,000 IU fish ${ }^{-1}$ hCG as priming and one or two resolving injections of 100 -

$822200 \mu \mathrm{g} \mathrm{kg}^{-1} \mathrm{GnRHa}$, while Besbes et al. (2020) treated with a priming dose of 10,000 IU $\mathrm{kg}^{-1} \mathrm{hCG}$ and resolving of $10,000 \mathrm{IU} \mathrm{kg}{ }^{-1} \mathrm{hCG}$ and $200 \mu \mathrm{g} \mathrm{kg}$. Those treatments 824 respectively resulted in: (i) 85\% spawning success with low $(<40 \%)$ to high $(<90 \%)$ fertilization percentages and fecundities of 1,649,000 eggs kg${ }^{-1} \mathrm{bw}$, (ii) $40 \%$ spawning 826 success with 75 to $80 \%$ fertilization and fecundities of $1,395,000 \mathrm{eggs} \mathrm{kg}^{-1} \mathrm{bw}$, and (iii) $100 \%$ success with $63 \%$ fertilization but low fecundities of 418,945 eggs kg-1 bw. In 828 general, these studies showed a highly variable spawning success and / or variable fertilization percentages whilst the present study presents a reliable spawning success, 830 from 85 to $100 \%$ depending on the spawning treatment, with one of the highest fecundities of 1,245,600 $\pm 552,117 \mathrm{eggs} \mathrm{kg}^{-1}$ bw obtained from females that were 832 successfully induced.

Regarding egg quality of fertilised eggs incubated in 96 well plates, $96 \pm 3 \%$ of fertilized 834 eggs developed embryos and hatched indicating a high egg quality. Moreover, larvae survived as long as 13 days at $21^{\circ} \mathrm{C}$ without exogenous feeding which is considered a 836 great improvement compared to the previous study by Ramos-Júdez et al. (2021), in which larvae survived no longer than $4 \mathrm{dph}$ at $24{ }^{\circ} \mathrm{C}$. Not only larvae survived longer 838 without the application of external feeding, but also larvae reared using mesocosm conditions demonstrated the potential to develop until juveniles, indicating that eggs and 840 larvae obtained after the induction of gametogenesis with rFsh and rLh could supply a hatchery. Indeed, larval development and growth in our study, using mesocosm rearing 842 conditions, was very similar to other published studies either using intensive or extensive conditions (Abraham et al., 1999; Besbes et al., 2020; El-Gharabawy and Assem, 2006;

844 Loi et al., 2020). Most of these studies, emphasized the effects of algal addition to the rearing tanks (green water technique) as the best way to optimize larval feeding on rotifers 846 due to its effect not only in facilitating the contrast but also improving the nutritional state and / or health of the rotifers (Tamaru et al., 1994). Larval growth in size was similar to 848 what Besbes et al. (2020) described, with larvae measuring $2.1 \mathrm{~mm}$ TL at hatching, and $2.96 \mathrm{~mm}$ TL at $4 \mathrm{dph}$, followed by a stagnated growth between $4 \mathrm{dph}$ and $11 \mathrm{dph}$ when 850 the larvae reached $3.5 \mathrm{~mm}$ TL. Growth was accelerated from $13 \mathrm{dph}$ to $35 \mathrm{dph}$ when they reached $5 \mathrm{~mm}$ TL and then until day 39 when they reached almost $7 \mathrm{~mm}$ TL. The 852 exponential growth recorded in the present study (Fig 14) was similar to that described by Besbes et al. (2020). Therefore, it was promising that the larvae reared in the 854 mesocosms demonstrated similar grow and development as other studies on flathead grey mullet larvae indicating the potential for hatchery production of larvae from adults that had gametogenesis-induced with rGths. 
Two critical periods have been described (Ignatius et al., 2017) during larval rearing of flathead grey mullet: one at days 2 - 3 post hatch due to the yolk sac resorption, a decrease in lipid reserves and an increase in specific gravity of the larvae, sinking to the bottom of 860 the tank and gradually perish (Maslova, 2011), and the other, at 8-11 dph during swim bladder formation with an excessive inflation, especially in intensive ("artificial") rearing

862 systems (Nash et al., 1977; Nash and Kuo, 1975). These periods would justify the higher mortalities from $85 \pm 18 \%$ survival at 2 dph to $55 \pm 17 \%$ at 9 dph and $8 \pm 11 \%$ at 12

864 dph observed in larvae maintained in 96-well plates without exogenous feeding. Although survival was not the aim of the larvae rearing in mesocosms, the main mortality problem

866 encountered was swimbladder hyperinflation. The larvae affected (see Fig 13G) remained floating in the water surface without moving and / or feeding on rotifers. This over

868 inflation has been observed in other marine fish larvae such as in meagre (Argyrosomus regius) larvae (Vallés and Estévez, 2013), and is often associated with stressful conditions

870 such as high light intensity, the use of long photoperiod, too early introduction of prey during larval rearing, or high larval density (Grotmol et al., 2005; Roo et al., 2010;

872 Villamizar et al., 2011) that induces the larvae to gulp too much air in the water surface inducing the hypertrophy of the swim bladder.

\section{Conclusion}

The approach described in the present study to induce oogenesis from previtellogenesis 876 or early vitellogenesis to the completion of oocyte growth and spawning using single chain recombinant gonadotropins ( $\mathrm{rFsh}$ and $\mathrm{rLh}$ ) produced in $\mathrm{CHO}$ cells, offers

878 replicability and guarantees a high success in spawning and high egg quality in flathead grey mullet. It was significant that in addition to inducing maturation from early 880 gametogenesis through to the production of viable male and female gametes, the rGths have also induced the processes and cascade of hormones and pheromones that control

882 reproductive behaviour and successful courtship in both females and males. From an applied point of view, the present protocol provides full control of reproduction with long884 term weekly rGth administration. The protocol provided high fecundities from flathead grey mullet females $\left(\sim 1,700,000\right.$ eggs female $\left.{ }^{-1}\right)$, with fertilisation and hatching of $\sim 50$ $886 \%$ of the spawned eggs. These fecundities, indicate that the induction of $6-7$ females $(\sim 1$ $\mathrm{kg}$ ) per season could permit a hatchery production of $\sim 1$ million fry, based on survivals 888 reported in the literature. This would reduce the need of many breeders and the quantity of hormones used. Besides, the present protocol can probably be applied to develop out890 of-season spawning and breeding programs.

\subsection{Acknowledgements}

Special thanks are due to Cristian Martínez Rodríguez, Alex Rullo Reverté, Esteban 894 Hernández, Magda Monllaó and Sandra Molas for taking care of the fish and larvae and the technical help in samplings. Thanks also to Marta Sastre, Edgar Bertumeu and Noelia

896 Gras for the help in steroids analysis. This study was funded by the Spanish Government, MINECO, project: RTI2018-094710-R-I00 coordinated by N.D. The participation of S.R. was funded, by a PhD grant from AGAUR (Government of Catalonia) co-financed by the European Social Fund. 
902

904

906

908

910

912

914

916

918

920

922

924

926

928

930

932

934

936

938

940

942

944

946

948

950

\subsection{References}

Abraham, M., Shiranee, P., Kishore Chandra, P., M, K., Charles, V.K., 1999. Embryonic and larval development of the striped mullet Mugil cephalus (L). Indian J. Fish. 2, $123-131$.

Aizen, J., Hollander-Cohen, L., Shpilman, M., Levavi-Sivan, B., 2017. Biologically active recombinant carp LH as a spawning-inducing agent for carp. J. Endocrinol. 232, 391-402. https://doi.org/10.1530/joe-16-0435

Aizen, J., Meiri-Ashkenazi, I., Tzchori, I., Sivan, B., Rosenfeld, H., 2005. Enhancing spawning in the grey mullet (Mugil cephalu) by removal of dopaminergic inhibition. Gen. Comp. Endocrinol. 142, 212-221. https://doi.org/10.1016/j.ygcen.2005.01.002

Besbes, R., Benseddik, A., Kokokiris, L., Changeux, T., Hamza, A., Kammoun, F., Missaoui, H., 2020. Thicklip (Chelon labrosus) and flathead (Mugil cephalus) grey mullets fry production in Tunisian aquaculture. Aquac. Reports 17, 100380. https://doi.org/10.1016/j.aqrep.2020.100380

Chauvigné, F., González, W., Ramos, S., Ducat, C., Duncan, N., Giménez, I., Cerdà, J., 2018. Seasonal-and dose-dependent effects of recombinant gonadotropins on sperm production and quality in the flatfish Solea senegalensis. Comp. Biochem. Physiol. Part A Mol. Integr. Physiol. 225, 59-64. https://doi.org/https://doi.org/10.1016/j.cbpa.2018.06.022

Chauvigné, F., Ollé, J., González, W., Duncan, N., Giménez, I., Cerdà, J., 2017. Toward developing recombinant gonadotropin-based hormone therapies for increasing fertility in the flatfish Senegalese sole. PLoS One 12, e0174387.

Chauvigné, F., Verdura, S., Mazón, M.J., Duncan, N., Zanuy, S., Gómez, A., Cerdà, J., 2012. Follicle-Stimulating Hormone and Luteinizing Hormone Mediate the Androgenic Pathway in Leydig Cells of an Evolutionary Advanced Teleost1. Biol. Reprod. 87. https://doi.org/10.1095/biolreprod.112.100784

De Monbrison, D., Tzchori, I., Holland, M., Zohar, Y., Yaron, Z., Elizur, A., 1997. Acceleration of gonadal development and spawning induction in the Mediterranean grey mullet, (Mugil cephalus): Preliminary studies. Bamidjeh 49, 214-221.

Divanach, P., Kentouri, M., 2000. Hatchery tehcniques for specific diversification in Mediterranean finfish larviculture, in: Basurco, B. (Ed.), Medieterranean Marine Aquaculture Finfish Species Diversification. Cahiers Options Méditerranéennes, vol 47 CIHEAM, Zaragoza, Spain, pp. 75-87.

El-Gharabawy, M., Assem, S., 2006. Spawning induction in the Mediterranean grey mullet Mugil cephalus and larval developmental stages. African J. Biotechnol. 5, 1836-1845.

Giménez, G., Estévez, A., Lahnsteiner, F., Zecevic, B., Bell, J.G., Henderson, R.J., Piñera, J.A., Sanchez-Prado, J.A., 2006. Egg quality criteria in common dentex $\begin{array}{llll}\text { (Dentex dentex). } & \text { Aquaculture } & 260,\end{array}$ https://doi.org/https://doi.org/10.1016/j.aquaculture.2006.06.028

González-Castro, M., Minos, G., 2016. Sexuality and Reproduction of Mugilidae., in: Crosetti, D., Blaber, S.J.M. (Eds.), Biology, Ecology and Culture of Grey Mullets. Boca Raton, FL: CRC Press, pp. 227-263.

González-López, W.Á., Ramos-Júdez, S., Giménez, I., Duncan, N.J., 2020. Sperm contamination by urine in Senegalese sole (Solea senegalensis) and the use of extender solutions for short-term chilled storage. Aquaculture 516, 734649. https://doi.org/https://doi.org/10.1016/j.aquaculture.2019.734649

Greeley, M., Calder, D., Wallace, R., 1987. Oocyte growth and development in the stripped mullet, Mugil cephalus, during seasonal ovarian recrudescence: Relationship to fecundity and size and maturity. Fish. Bull. 85. 
Grotmol, S., Kryvi, H., Totland, G.K., 2005. Deformation of the notochord by pressure from the swim bladder may cause malformation of the vertebral column in cultured Atlantic cod Gadus morhua larvae: a case study. Dis. Aquat. Organ. 65, 121-128. https://doi.org/10.3354/dao065121

Hagiwara, A., Oozeki, Y., Eda, H., Lee, C.-S., 1992. Developmental Changes of Food Selectivity of Striped Mullet Mugil cephalus during the Larval Stage. Nippon SUISAN GAKKAISHI 58, 1381. https://doi.org/10.2331/suisan.58.1381

Hayakawa, Y., Morita, T., Kitamura, W., Kanda, S., Banba, A., Nagaya, H., Hotta, K., Sohn, Y., Yoshizaki, G., Kobayashi, M., 2008. Biological activities of single-chain goldfish follicle-stimulating hormone and luteinizing hormone. Aquaculture 274, 408-415. https://doi.org/10.1016/j.aquaculture.2007.12.002

Ignatius, B., Joseph, I., Muktha, M., 2017. Mugil cephalus Linnaeus, 1758, in: Ranjan, R., Muktha, M., Ghosh, S., Gopalakrishnan, A., Gopakumar, G., Joseph, I. (Eds.), Prioritized Species for Mariculture in India. ICAR-CMFRI, Kochi, India, pp. 237244.

Kamei, H., Kaneko, T., Aida, K., 2006. In vivo gonadotropic effects of recombinant Japanese eel follicle-stimulating hormone. Aquaculture 261, 771-775. https://doi.org/10.1016/j.aquaculture.2006.08.039

Kobayashi, M., Hayakawa, Y., Park, W., Banba, A., Yoshizaki, G., Kumamaru, K., Kagawa, H., Kaki, H., Nagaya, H., Sohn, Y.C., 2010. Production of recombinant Japanese eel gonadotropins by baculovirus in silkworm larvae. Gen. Comp. Endocrinol. 167, 379-386. https://doi.org/https://doi.org/10.1016/j.ygcen.2010.01.003

Kobayashi, M., Morita, T., Ikeguchi, K., Yoshizaki, G., Suzuki, T., Watabe, S., 2006. In vivo biological activity of recombinant goldfish gonadotropins produced by baculovirus in silkworm larvae. Aquaculture 256, 433-442. https://doi.org/10.1016/j.aquaculture.2006.01.016

Kumar, P., Arasu, A.R.T., Kailasam, M., Sukumarran, K., Subburj, R., Tyagraj, G., Natarajan, M., 2015. Gonadal development and steroid hormone profile of wild caught grey mullet (Mugil cephalus). Biol. Rhythm Res. 46, 601-610. https://doi.org/10.1080/09291016.2015.1034974

Loi, B., Papadakis, I.E., Leggieri, F., Giménez Papiol, G., Vallainc, D., 2020. Ontogeny of the digestive system and eye of reared flathead grey mullet, Mugil cephalus (Linnaeus, 1758), and evaluation of lipid deposition in the liver according to the feeding protocol. Aquaculture 735386. https://doi.org/https://doi.org/10.1016/j.aquaculture.2020.735386

Lubzens, E., Young, G., Bobe, J., J, C., 2010. Oogenesis in teleosts: How fish eggs are formed. Gen Comp Endocrinol. 165, 367-389. https://doi.org/10.1016/j.ygcen.2009.05.022

Mañanós, E., Duncan, N., Mylonas, C., 2009. Reproduction and control of ovulation, spermiation and spawning in cultured fish., in: Cabrita, E., Robles, V., Herráez, M. (Eds.), Methods in Reproductive Aquaculture: Marine and Freshwater Species. Taylor and Francis Group LLC, CRC Press, pp. 3-80.

Maslova, O.N., 2011. Dynamics of chemical composition of the Black Sea gray mullet Mugil cephalus in the period of early ontogenesis and its dependence on temperature and salinity. J. Ichthyol. 51, 382-391. https://doi.org/10.1134/S0032945211030040

McDonough, C., Roumillat, W.A., Wenner, C.A., 2005. Sexual differentiation and gonad development in striped mullet (Mugil cephalus L.) from South Carolina estuaries. Fish. Bull. 103, 601-619.

Molés, G., Hausken, K., Carrillo, M., Zanuy, S., Levavi-Sivan, B., Gómez, A., 2020. 

113555. https://doi.org/https://doi.org/10.1016/j.ygcen.2020.113555

1004

1006

1008

1010

1012

1014

1016

1018

1020

1022

1024

1026

1028

1030

1032

1034

1036

1038

1040

1042

1044

Mylonas, C., Zohar, Y., 2007. Promoting oocyte maturation, ovulation and spawning in farmed fish, in: The Fish Oocyte: From Basic Studies to Biotechnological Applications. pp. 437-474. https://doi.org/10.1007/978-1-4020-6235-3_15

Peñaranda, D.S., Gallego, V., Rozenfeld, C., Herranz-Jusdado, J.G., Pérez, L., Gómez, A., Giménez, I., Asturiano, J.F., 2018. Using specific recombinant gonadotropins to induce spermatogenesis and spermiation in the European eel (Anguilla anguilla). Theriogenology 107 , 6-20. https://doi.org/https://doi.org/10.1016/j.theriogenology.2017.11.002

Ramachandran, B., Natesan, M., 2016. Assessment of sperm quality and short term preservation of sperm in grey mullet Mugil cephalus Linnaeus, 1758. Indian J. Fish. 63. https://doi.org/10.21077/ijf.2016.63.4.61001-23

Ramos-Júdez, S., Chauvigné, F., González-López, W.Á., Rosenfeld, H., Cerdà, J., Giménez, I., Duncan, N., 2021. Providing recombinant gonadotropin-based therapies that induce oogenesis from previtellogenic oocytes to produce viable larvae in a teleost, the flathead grey mullet (Mugil cephalus). Aquaculture 736418. https://doi.org/https://doi.org/10.1016/j.aquaculture.2021.736418

Roo, J., Hernandez-Cruz, M., Borrero, C., Schuchardt, D., Fernández-Palacios, H., 2010. Effect of larval density and feeding sequence on meagre (Argyrosomus regius; Asso, 1801) larval rearing. Aquaculture 302, 82-88. https://doi.org/10.1016/j.aquaculture.2010.02.015

Schulz, R.W., de França, L.R., Lareyre, J.-J., LeGac, F., Chiarini-Garcia, H., Nobrega, R.H., Miura, T., 2010. Spermatogenesis in fish. Gen. Comp. Endocrinol. 165, 390411. https://doi.org/https://doi.org/10.1016/j.ygcen.2009.02.013

Schulz, R.W., Miura, T., 2002. Spermatogenesis and its endocrine regulation. Fish Physiol. Biochem. 26, 43-56. https://doi.org/10.1023/A:1023303427191

Tamaru, C.S., Murashige, R., Lee, C.-S., 1994. The paradox of using background phytoplankton during the larval culture of striped mullet, Mugil cephalus L. Aquaculture 119, 167-174. https://doi.org/https://doi.org/10.1016/00448486(94)90173-2

Valdebenito, I., Paiva, L., Berland, M., 2011. Atresia folicular en peces teleósteos: una revisión. Arch. Med. Vet. 43, 11-25.

Villamizar, N., Blanco-Vives, B., Migaud, H., Davie, A., Carboni, S., Sánchez-Vázquez, F.J., 2011. Effects of light during early larval development of some aquacultured teleosts: A review. Aquaculture 315, 86-94. https://doi.org/https://doi.org/10.1016/j.aquaculture.2010.10.036

Whitfield, A.K., Panfili, J., Durand, J.-D., 2012. A global review of the cosmopolitan flathead mullet Mugil cephalus Linnaeus 1758 (Teleostei: Mugilidae), with emphasis on the biology, genetics, ecology and fisheries aspects of this apparent species complex. Rev. Fish Biol. Fish. 22, 641-681. https://doi.org/10.1007/s11160012-9263-9

Yashouv, A., 1969. Preliminary report on induced spawning of M. cephalus (L.) reared in captivity in freshwater ponds. Bamidgeh 21, 19-24. 